\title{
LOS BANQUEROS EUROPEOS Y LOS EMPRESTITOS ARGENTINOS: RIVALIDAD Y COLABORACION: $1880-1890$
}

\author{
CARLOS MARICHAL \\ Universidad Autónoma Metropolitana de México
}

\author{
"Llegó a imaginarse que la Bolsa sería \\ una especie de Minotauro..." \\ Julián MARTel, La Bolsa (1891)
}

La quiebra de la poderosa casa bancaria de Baring Brothers, en noviembre de 1890, sacudió violentamente al mercada de capitales en Londres, desatando una corta pero intensa crisis financiera internacional. Sus efectos se hicieron sentir no tan sólo en Inglaterra y varios centros financieros de la Europa continental, sino, además, en Sudamérica. Las ondas expansivas y destructivas alcanzaron con particular fuerza a la opulenta metrópolis de Buenos Aires, dando lugar al desplome vertical de los valores de docenas de empresas financieras, mercantiles y ferroviarias que operaban en el Río de la Plata ${ }^{1}$. El hundimiento de la Bolsa bonaerense fue seguido al poco tiempo por la bancarrota de las dos principales entidades bancarias del país, el Banco Nacional y el Banco de la Provincia de Buenos Aires, casi inmediatamente forzando la suspensión de pagos internacionales por parte del Gobierno. En esta forma dramática y hasta cataclísmica se cerraba un decenio - el de 1880-1890 - signado por el más impresionante boom financiero que había conocido cualquier país latinoamericano hasta esas fechas.

Para numerosos observadores contemporáneos y para un amplio espectro de historiadores económicos posteriores, la crisis de 1890 reflejaba las consecuencias de aquella combinación de imprudencia y especulación voraz que hizo presa de banqueros londinenses y gobernantes argentinos del período ${ }^{2}$. Por otra parte, el carácter específicamente anglo-argentino de la crisis daba pie a meditar sobre el grado de interpenetración existente entre las Bolsas de Londres y Buenos Aires en los febriles años del 80. Diversos escritores hicie-

\footnotetext{
' Sobre la crisis de 1890 en el Río de la Plata, véase Sommi (1948), capitulo 5; Ford (1956), Hodge (1970).

2 Este tipo de enfoque puede encontrarse en Ferns (1968), pp. 437-438, y en Williams (1920), capítulo 8.
} 
ron hincapié en que la verdadera raíz de la catástrofe se cifraba en la exage. rada inclinación, $y$ hasta obsesión, de los banqueros británicos por la compraventa de valores privados y públicos argentinos. Pero también fue cierto que, desde el principio del crash del 90 , prestigiosas revistas financieras, como el Soutb American Journal, argumentaron que los problemas económicos iban más allá de los excesivos compromisos asumidos por la casa Baring u otros mercbant banks ingleses ${ }^{3}$. Debía tenerse en cuenta que el estado crítico de centenares de empresas ferroviarias en Estados Unidos, la crisis bancaria en Francia y los vaivenes de las finanzas rusas eran, asimismo, elementos poderosos que contribuyeron a agudizar la situación, si no a desatarla.

En las páginas que siguen, nuestro objetivo consiste esencialmente en señalar que, aun en la propia Argentina, el grado de complejidad y de internacionalización de las relaciones financieras traspasaba la aparentemente simple y simbiótica vinculación entre Buenos Aires y Londres. La participación de banqueros franceses y alemanes en un considerable número de los mayores empréstitos nacionales y provinciales de Argentina reflejaba la faceta multilateral del imperialismo financiero desde 1880 en adelante. A ello puede agregarse el interés manifestado por parte de algunos grupos bancarios belgas, italianos y españoles en los negocios rioplatenses de la época, aunque en un grado muy inferior al de los tres países industriales más poderosos de Europa ${ }^{4}$.

El examen de los paralelos y contrastes entre las estrategias de los financieros de Londres, París y Berlín, en lo que atañe a las emisiones de empréstitos en la década de los ochenta, plantea una amplia gama de interrogantes. Pero, dada la brevedad del presente ensayo, nos limitaremos a tres de ellos, que iremos analizando en cada una de las secciones respectivas sobre el papel de los grupos bancarios franceses, alemanes y británicos. El primer problema de tipo general que nos interesa explorar se refiere al carácter marcadamente cíclico de las emisiones de los empréstitos argentinos a partir de 1880 . La segunda cuestión se centra en un breve estudio de las condiciones prevalecientes en las distintas Bolsas europeas y, en especial, el rol de numerosas casas bancarias competidoras por abrir y conquistar el mercado para los títulos argenti-

${ }^{3}$ El 22 de noviembre de 1890 , en plena crisis, el South American Journal se refería a la firma de Baring Brothers afirmando que "sus operaciones en América del Norte $y$ en todas las naciones de Europa, todavia mayores que las del Río de la Plata, junto con la prolongada y seria depresión de los bonos norteamericanos, debieron tener una influencia muy grave sobre sus negocios. Finalmente, vino ese golpe inesperado cuando el Gobierno ruso decidió retirar la enorme suma de aproximadamente 5 millones de libras esterlinas que tenía depositada en esa casa bancaria".

- Entre las firmas anglo-españolas deben citarse, en particular, las casas bancarias de Cristóbal Murrieta and Co. y la de Ibánez Vega and Co., que operaban en Londres como "merchant banks" y que habian participado en empréstitos externos argentinos desde 1870. Para mayor información véanse los informes sobre crédito público de las memorias anuales del Ministerio de Hacienda, 1870-1875. 
nos. Por último, nos interesa formular un diagnóstico acerca de la relación, algo contradictoria, que existía entre los flujos mercantiles y las exportaciones de capital. Debemos agregar al respecto que el enfoque comparativo sugiere una serie de respuestas que tienden a ser algo distintas para cada uno de los principales grupos bancarios estudiados.

\section{Los años ocbenta, el Estado y los ciclos de empréstitos}

El decenio de 1880-90 fue el primer período de la historia decimonónica de Argentina para el cual se podría afirmar que los capitales extranjeros llegaron a desempeñar un papel realmente decisivo en el proceso de desarrollo económico ${ }^{5}$. El oro europeo, que entonces afluyó en cantidades importantes al Río de la Plata, contribuyó a la construcción de una vasta red de ferrocarriles, a la modernización de las principales ciudades y puertos, al establecimiento de un amplio sistema bancario y a la creación y multiplicación de empresas comerciales, de servicios y de tierras.

Los capitales externos, sin embargo, no cruzaban el Atlántico de motus propio. Uno de los factores decisivos que atrajo a los fondos europeos fue la política de intenso endeudamiento adoptada por el Estado argentino. Los gobernantes rioplatenses del 80 vislumbragron que el oro extranjero podía ofrecer la solución a una gran parte de sus problemas fiscales $\mathrm{y}$, al mismo tiempo, proporcionaría una garantía para un rápido proceso de desarrollo económico. Fue el Gobierno nacional el que tomó la primera iniciativa en abrir negociaciones con los banqueros de Londres, París y Berlín; pero pronto fue seguido por los dirigentes de los gobiernos provinciales y municipales, los gerentes de bancos estatales y los administradores de empresas ferroviarias gubernamentales, todos los cuales estaban igualmente ansiosos por conseguir el apoyo financiero externo.

Para fines del 80 , el número de agencias estatales argentinas que estaban compitiendo por préstamos en los mercados de capitales europeos había sobrepasado todas las expectativas ${ }^{6}$. Y el volumen de los empréstitos externos también estaba batiendo marcas. Entre 1880 y 1890, los gobiernos nacionales, provinciales y municipales argentinos contrataron un total nominal de cerca de 400 millones de pesos oro ( 80 millones de libras esterlinas) en em-

s Antes de 1880 se había iniciado una corriente relativamente reducida de capitales británicos hacia el Rio de la Plata. Al respecto, véanse Ferns (1968), capítulo XI, y Platt (1983).

- Entre las agencias estatales deben citarse, en particular, el Banco Hipotecario Nacional, el Banco Hipotecario de la Provincia de Buenos Aires, el Banco Nacional, el Ferrocarril Oeste de la Provincia de Buenos Aires y los organismos oficiales de crédito de las provincias de Santa Fe, Entre Ríos y Córdoba. 
préstitos externos. A lo cual habría que añadir muchos millones más en calidad de bonos hipotecarios de los bancos estatales (las famosas «cédulas») que se colocaron en la mayoría de los mercados financieros europeos contemporáneos ${ }^{7}$.

Un índice de la importancia que fue adquiriendo Argentina como receptor de capitales lo sugieren los datos de la Bolsa londinense: en los años de 18861889 , los títulos argentinos (públicos y privados) constituyeron aproximadamente el 20 por 100 del total de valores extranjeros de cartera emitidos en la capital británica, el centro monetario internacional más importante de la época. (Véase gráfico 3.)

Que las políticas adoptadas por los gobiernos de Roca (1880-86) y Juárez Celman (1886-90) con respecto a la «internacionalización» de la deuda estatal influenciaron los flujos de capital por el lado de la demanda es, sin duda, cierto. Pero tampoco debe ignorarse que la otra cara de la moneda consistía en la considerable oferta de dinero que existía en las Bolsas europeas. Es decir, los factores de «empuje» eran igualmente importantes que las fuerzas de "atracción»". La forma en que se canalizaban estos fondos dependía en buena medida de las estrategias implementadas por las casas bancarias, ya que ellas ejencian un rol preponderante en los mercados bursátiles. Por este motivo debemos detenernos para considerar hasta qué punto no fueron realmente los políticos argentinos, sino los banqueros extranjeros, los que tocaban las teclas claves de la economía internacional y, por ende, de la nacional. Después de todo, eno habían sido los financieros europeos los que instaron a los dirigentes argentinos a solicitar cada vez mayores cantidades de fondos del exterior? Su responsabilidad era manifiesta desde un principio, como lo señalaba el gerente del principal banco inglés de Buenos Aires en una carta dirigida a sus superiores en Londres, en el mes de junio de 1881:

«Durante los últimos seis meses, los capitalistas europeos han estado sugiriendo a los hombres en el poder en este país que el crédito argentino es virtualmente ilimitado... La superabundancia del dinero en Europa y las bajas tasas de interés allí quizá induzcan a los inversores a responder afirmativamente a las solicitudes [argentinas] a pesar de los posibles riesgos» 9

\footnotetext{
7 Williams (1920) calcula que el valor de las cédulas de los bancos hipotecarios argentinos emitidos en Europa entre 1886 y 1890 alcanzó a 170 millones de pesos oro (aproximadamente 34 millones de libras esterlinas).

'Sobre la relativa importancia de las fuerzas de "empuje" y de "atracción", véase Ford (1971), pp. 217-223.

- Joslin (1963), p. 118.
} 
¿Pero cuáles eran los motivos que impulsaban a los banqueros británi$\cos$ y franceses -en primer lugar- a transferir los capitales disponibles hacia el Río de la Plata? Consideremos, aunque sea brevemente, algunas posibles explicaciones que puedan dar razón del inicio de estas corrientes a partir del año clave de 1880 . Un primer motivo ostensible — subrayado por numerosos autores- consistía en que, aun siete años después de la gran crisis internacional de 1873 , la recesión agrícola e industrial continuaba deprimiendo a importantes sectores de las economías europeas. Mientras tanto, las perspectivas de crecimiento en las «tierras nuevas», como los Estados Unidos, Australia o Argentina, parecían mucho más halagüeñas. En todas ellas, la expansión de las fronteras agrícola-ganaderas estaba produciendo un incremento de las exportaciones primarias, al tiempo que estimulaba un rápido proceso de desarrollo ferroviario y urbano ${ }^{10}$. Por otra parte, el alto nivel de los salarios en estos países "nuevos» atraía un creciente flujo de emigrantes europeos, lo que en sí mismo constituía un factor dinamizador de la economía.

Pero, limitándonos más específicamente a la región latinoamericana, habría que preguntar por qué Argentina, en particular, estaba destinada a recibir un trato tan preferencial por parte de los capitalistas europeos desde 1880 . Recordemos, en primer término, que precisamente en ese año estaban en guerra dos de los países latinoamericanos que anteriormente habían figurado entre los clientes más asiduos de la plaza de Londres: Chile y Perú. Los inversores europeos temblaban ante el peligro (nada imaginario) de ver que sus inversiones en ambos países podían desaparecer de la noche a la mañana. Más al Norte, la situación no era sustancialmente diferente: México había repudiado el pago de su deuda externa desde 1867, hecho que no se modificaría hasta después de 1884. Al mismo tiempo, países chicos como Costa Rica, Ecuador o Paraguay -entre otros- no habían pagado ni los intereses ni la amortización sobre sus empréstitos desde la crisis de 1873. El caso de Bolivia era particularmente ilustrativo: los litigios entre el comité de tenedores de bonos en Europa y el Gobierno boliviano se prolongaban año tras año sin resultados auspiciosos para los primeros. Así lo testimoniaba en 1883 el informe de una reputada guía bursátil británica, señalando con desprecio que "iel estado actual de las finanzas de Bolivia es totalmente desconocido!»".

Dentro de este panorama relativamente desolador para aquellos rentistas o banqueros interesados en invertir dinero en bonos latinoamericanos con altas tasas de interés y bajos precios de compra, Argentina aparecía sumamente atractiva. Políticamente estable, con excedentes comerciales durante

10 En el caso argentino esta explicación tradicional está expuesta, por ejemplo, en Cortés Conde y Gallo (1973).

1 Fenn (1883), p. $\$ 79$. 
los últimos años y con enormes posibilidades de expansión a nivel urbano y rural, el país resultaba una presa irresistible para los financieros europeos.

No obstante, este repentino y fervoroso interés por los negocios rioplatenses no resultó tan duradero como esperaban los gobernantes argentinos. Durante los años de 1880-82, casi todos los empréstitos emitidos en Europa encontraron una recepción extremadamente favorable, pero después de la crisis bancaria que tuvo lugar en París desde principios de 1882, este interés fue decayendo. La crisis financiera comenzaba a vislumbrarse poco después en Londres. El sorpresivo fracaso de los empréstitos nacionales argentinos de 1883 y 1884 -asumidos tentativamente por las poderosas casas de Baring Brothers y J. S. Morgan - marcaba de alguna manera el fin de un primer pero breve ciclo de endeudamiento externo ${ }^{12}$.

La problemática situación financiera en Europa tuvo importantes consecuencias en Argentina, generando una breve crisis mercantil y financiera local, que se agudizó en 1885. El presidente Roca se vio obligado entonces a enviar al ex ministro Carlos Pellegrini a París y Londres para sondear a los banqueros acerca de la posibilidad de negociar un gran empréstito de rescate que contribuyera a salvar el crédito argentino en los mercados internacionales. El delegado argentino cumplió sus objetivos exitosamente, uniendo a las firmas londinenses de Baring y Morgan en un sindicato bancario, al cual se agregó un grupo de bancos franceses liderados por el Banque de Paris et Pays Bas ${ }^{13}$. Conjuntamente pudieron emitir el nuevo préstamo, pero Pellegrini fue ácidamente criticado por haber aceptado condiciones que fueron calificadas como las más onerosas de la historia financiera argentina ${ }^{14}$.

A partir de mediados de 1886 , la situación financiera internacional mejoró repentinamente. Con el cambio de coyuntura, las autoridades gubernamentales se vieron sorpresivamente acosadas por una horda de bancos, grandes y chicos, de Londres, París, Amberes, Berlín y Frankfort, sedientos de realizar lucrativos negocios en la emisión y venta de valores argentinos ${ }^{15}$. El

12 Sobre la crisis de 1882 en Francia, véase Bouvier (1960). Sobre el fracaso de los empréstitos Morgan y Baring de 1883 y 1884, véase Jones (1972).

13 En una carta dirigida al ministro de Hacienda desde París (4 de mayo de 1885), Pellegrini afirmaba que: "Las bases (para el nuevo empréstito) son anular los contratos existentes, refundir los dos sindicatos (inglés y trancés) en uno y, tal vez, agregar un nuevo grupo alemán...", Archivo de la Deuda Externa (Ministerio de Economía, Buenos Aires), carpeta 2096.

14 Véanse los comentarios de quien fue cónsul argentino en Londres entre 1870 y 1885; Guerrico (1887), pp. 23, 25 y 26.

is Una ilustración particularmente ilustrativa de este fenómeno se encuentra en un artículo de la prestigiosa revista financiera de Londres, el Money Market Review (26 de noviembre de 1887), que señalaba: "Holders of Argentine securities may be invited to consider how vast and widespread are the interests which are concerned in upholding Argentine credit. Four or five of the greatest private financial firms in London as well as some of the best accredited Banks and other 
Gobierno federal se entregó con fervor al juego especulativo que tenía lugar en las Bolsas europeas, solicitando empréstito tras empréstito y otorgando subsidios extraordinariamente generosos a un gran número de empresas extranjeras que proponían realizar diversas «obras productivas», especialmente en el sector de construcción de ferrocarriles. Simultáneamente, los gobiernos provinciales, los municipios, los bancos hipotecarios estatales y otras agencias gubernamentales se lanzaron a los mercados europeos para obtener sus respectivas cuotas del oro extranjero.

La fiebre especulativa alcanzó su apogeo en 1888, al ingresar cerca de 250 millones de pesos oro al país en calidad de préstamos e inversiones extranjeras directas. Al año siguiente, sin embargo, el interés de los inversores europeos en las operaciones rioplatenses comenzó a enfriarse. Pero, aparentemente, ni el Gobierno argentino ni la mayoría de los banqueros quisieron percatarse del significado de los cambios que comenzaban a socavar las Bolsas europeas. El derrumbe no debía estar lejos, como indicaba Pellegrini a mediados de 1889 en una carta escrita desde París, en la que se señalaban los peligros de continuar con la misma política especulativa:
"Aquí empieza a descomponerse la plaza para las cosas argenti- nas. El Financial News, dice días pasados: "El mercado sin nove- dad; la única noticia de sensación es que dos días no se ha pre- sentado ningún nuevo empréstito [argentino]...! Ahora se anun- cia un empréstito de cuarenta millones para el Gobierno Nacional y veinte y cinco millones para Córdoba! Hay además una por- ción de ferrocarriles garantidos que aún no se han lanzado... Aún tiene Baring en el buche la mayor parte de los cincuenta millo- nes de las Obras de Salubridad..." ${ }^{16}$.

El corto pero muy intenso ciclo de transferencia de capitales se terminaba. Desde mediados de 1890 , los mercados de capitales europeos ya no estaban dispuestos a ofrecer más fondos y, poco después, estallaría la crisis.

Ya hemos indicado que no es nuestro propósito intentar una explicación de la crisis en sí, sino de las condiciones subyacentes a lo largo de los años ochenta que generaron esta situación. Entre ellas hemos subrayado, en primera instancia, el carácter marcadamente cíclico de los flujos de capital externo, con períodos de auge entre 1880 y 1883 y, especialmente, durante los años 1886-89. Pero para aclarar por qué fueron tan intensos aquellos ciclos

Joint-Stock companies are identified with her loan issues; and so likewise are leading establishments at Paris, Berlin and many other continental centres of finance. It is not as in the old days when the relations of the Argentine Government with Europe were conducted only through one or two channels."

${ }_{16}$ Pellegrini (1941), volumen II, p. 216. 
breves es primordial tener en cuenta el carácter verdaderamente multilateral de la exportación de capitales a Argentina desde esta época. En otras palabras, los movimientos concurrenciales y simultáneos de fondos de Inglaterra, Francia, Alemania y otros países europeos bacia el Río de la Plata en períodos bastante cortos fueron, quizá, el factor más decisivo en desatar olas expansivas tan fuertes y abruptas. A su vez, este proceso desató una inusitada rivalidad entre múltiples casas bancarias europeas que deseaban aprovecharse de una súbita eclosión de posibilidades para realizar negocios en un terreno nuevo que ofrecía beneficios superiores a los que, normalmente, regían en el mercado de préstamos intraeuropeos.

Procederemos, por consiguiente, a hacer el repaso de las principales estrategias de carácter financiero y mercantil que indujeron a los banqueros franceses, alemanes y británicos, respectivamente, a intensificar sus operaciones en el Río de la Plata en este decenio. Comenzaremos con los franceses, pues fueron los primeros en romper el monopolio que habían ejercido los financieros ingleses en el manejo de las finanzas externas argentinas hasta entonces.

\section{La estrategia de la banca francesa en el Río de la Plata}

Si bien casi todos los estudios que tratan el tema de la economía argentina durante el siglo xIx enfatizan el papel del imperialismo británico, son muy pocos los que hacen mención de la participación de capitales franceses. Y ello resulta particularmente engañoso al analizar la década del 80 , ya que a lo largo de este período no sólo se negociaron un buen número de empréstitos con los banqueros parisinos, sino que, además, se mantuvo un grado muy intenso de intercambio comercial franco-argentino.

Es cierto que hasta 1880 la banca francesa no había efectuado ninguna operación financiera de envergadura en el Río de la Plata. Los contados préstamos externos emitidos por el Gobierno argentino fueron negociados exclusivamente con firmas bancarias de Londres en los años de 1865-1873. Pero a partir de la elección del presidente Roca, en 1880, tales circunstancias se modificaron, ya que las autoridades argentinas procedieron a adoptar una política de abierta «internacionalización» en sus relaciones financieras. De hecho, el primer empréstito nacional propuesto por la nueva Administración fue objeto de una fuerte rivalidad entre tres firmas bancarias inglesas, dos casas financieras anglo-españolas y dos grupos franceses ${ }^{17}$.

${ }^{17} \mathrm{El}$ empréstito era por 2.450 .000 libras esterlinas y estaba destinado fundamentalmente a financiar la construcción de los ferrocarriles estatales "Central Norte" y "Andino". Para detalles, véanse Peña (1907) y Agote (1887). 
Cada competidor ofreció condiciones algo distintas en sus conversaciones con el Gobierno, lo que, naturalmente, hizo pensar a los dirigentes políticos que debían intentar alentar la rivalidad entre los financieros europeos con la finalidad de obtener los mejores resultados posibles. Sin embargo, las ofertas resultaron algo decepcionantes. Al principio, la casa de Stern Brothers, de Londres, ofreció pagar 78 (sobre el valor nominal de 100 de cada bono), aunque luego, y debido a la competencia de Baring Brothers, se vieron obligados a aumentar la oferta a 81 , en marzo de 1881. A pesar de ello, el agente de Baring en Buenos Aires consideraba que el Gobierno acabaría negociando con su firma, y estimó que 85 sería un precio razonable. Pero los directores londinenses de Baring no quisieron hacer la oferta «en firme», esdecir, garantizando que se pagaría ese precio mínimo, con lo cual las negociaciones se complicaron considerablemente.

Finalmente, el Gobierno argentino optó por la propuesta del sindicato francés liderado por los bancos Comptoir d'Escompte y Paribas, que ofrecieron 82 «en firme». El contrato del empréstito fue firmado por el ministro de Hacienda argentino con la firma bonaerense de Bemberg Heimendahl, que representaba al sindicato parisino. La opinión pública de Buenos Aires se mostró claramente disgustada con la operación, aunque ello no se debía a la participación gala en los negocios financieros, sino más bien a lo que se consideraba eran condiciones poco favorables para el Gobierno. De allí que diversos artículos en la prensa señalaban que se debía haber pedido, por lo menos, cinco puntos más en las negociaciones.

El ministro de Hacienda inclusive llegó a mencionar al agente Bouwer, de Baring Brothers, que el gabinete había deseado aceptar la oferta de Baring's, pero que el general Roca insistió en que se aceptara la mejor oferta «en firme», pues temía que surgieran dificultades en el último momento a raíz de las fuertes tensiones en la frontera argentino-chilena ${ }^{18}$. En todo caso, la decisión de Roca benefició enormemente a los banqueros del sindicato francés, ya que pudieron sacar entre cuatro y cinco millones de francos como recompensa por sus servicios, lo que no era nada despreciable para este tipo de operación.

El embajador argentino en París escribió al ministro de Hacienda en Buenos Aires, el 4 de junio de 1881, confirmando el éxito de la emisión:

«El empréstito se ha cubierto más de 18 veces en Francia... Es en efecto un gran triunfo, pues la impresión desfavorable que han dejado en este mercado los desacreditados empréstitos de México, Perú y Honduras hacían dudoso este empréstito.... ${ }^{19}$.

1 Jones (1972), p. 5.

19 Carta del embajador en París, Mariano Balcarce, al ministro argentino de Hacienda, fechada el 4 de junio de 1881, Archivo de la Deuda Externa (Ministerio de Economía, Buenos Aires), carpeta 2088. 
¿Qué explicaba el éxito en la venta de los bonos argentinos de 1881 en París? Sin duda, ciertos elementos puramente coyunturales - como podía ser la súbita abundancia de capitales-, pero deben explicarse, asimismo, aquellas tendencias subyacentes que contribuyen a explicar por qué los banqueros franceses siguieron compitiendo por los préstamos rioplatenses a lo largo del decenio.

El mismo sindicato encabezado por Paribas y Comptoir d'Escompte, e incluyendo a otras casas fuertes como la Société Générale y L. Cahen d'Anvers, luchó exitosamente por obtener una participación en la emisión de otros empréstitos argentinos de $1881,1882,1883$ y 1885 . En conjunto, la banca parisina fue responsable de aproximadamente el 59 por 100 del total bonos del Gobierno nacional vendidos en Europa entre 1880 y 1885 , aunque debe señalarse que en materia de bonos provinciales iban enteramente a la zaga de los banqueros británicos. (Véanse cuadros 1 y 2.) Estas circunstancias no sólo révelaban el nuevo peso del imperialismo financiero francés en América del Sur, sino que, además, provocaron considerables recelos por parte de los banqueros británicos, ya algo acostumbrados a ejercer un virtual monopolio en el terreno de los préstamos argentinos.

Entre 1886 y 1890 , la banca francesa tuvo un rol algo menos relevante en la esfera de las finanzas del Gobierno nacional, pero, en cambio, su participación en la colocación de bonos de gobiernos provinciales y en la venta de cédulas hipotecarias argentinas fue cada vez más destacada ${ }^{20}$. La mayoría de estas operaciones, relativamente pequeñas pero numerosas, fueron realizadas a través de una serie de firmas intermediarias de Buenos Aires, en particular las de Bemberg y Cía., Portalis y Cía. y Mallman y Cía., las cuales posteriormente efectuaban arreglos para la colocación de los valores con una serie de casas bancarias francesas y belgas que tendían a especializarse en negocios especulativos y en diversos mercados financieros. De esta manera se iba extendiendo la compraventa de títulos argentinos de variada índole hacia nuevas esferas que traspasaban el radio formal de acción de las grandes Bolsas europeas, llegando a una clientela más amplia e heterogénea de inversores.

La actuación de los diversos bancos franceses que operaban con valores argentinos durante el decenio de los ochenta respondia a cambios que se fueron dando en los mercados de capitales de Francia. Entre 1878 y 1882 se había producido un extraordinario auge financiero en la Bolsa de París y en

20 Un periódico tinanciero inglés señalaba que aunque una parte de los treinta y cinco y pico de millones de libras esterlinas de cédulas emitidas en Europa entre 1886 y 1890 fueron colocados en Londres, "la mayoría de las varias emisiones pasaron a manos de inversores del continente europeo, a través de casas bancarias de París, Hamburgo, Berlín, Amsterdam, Frankfort y otros centros financieros". Money Market Review, 29 de mayo de 1890, p. 702. 


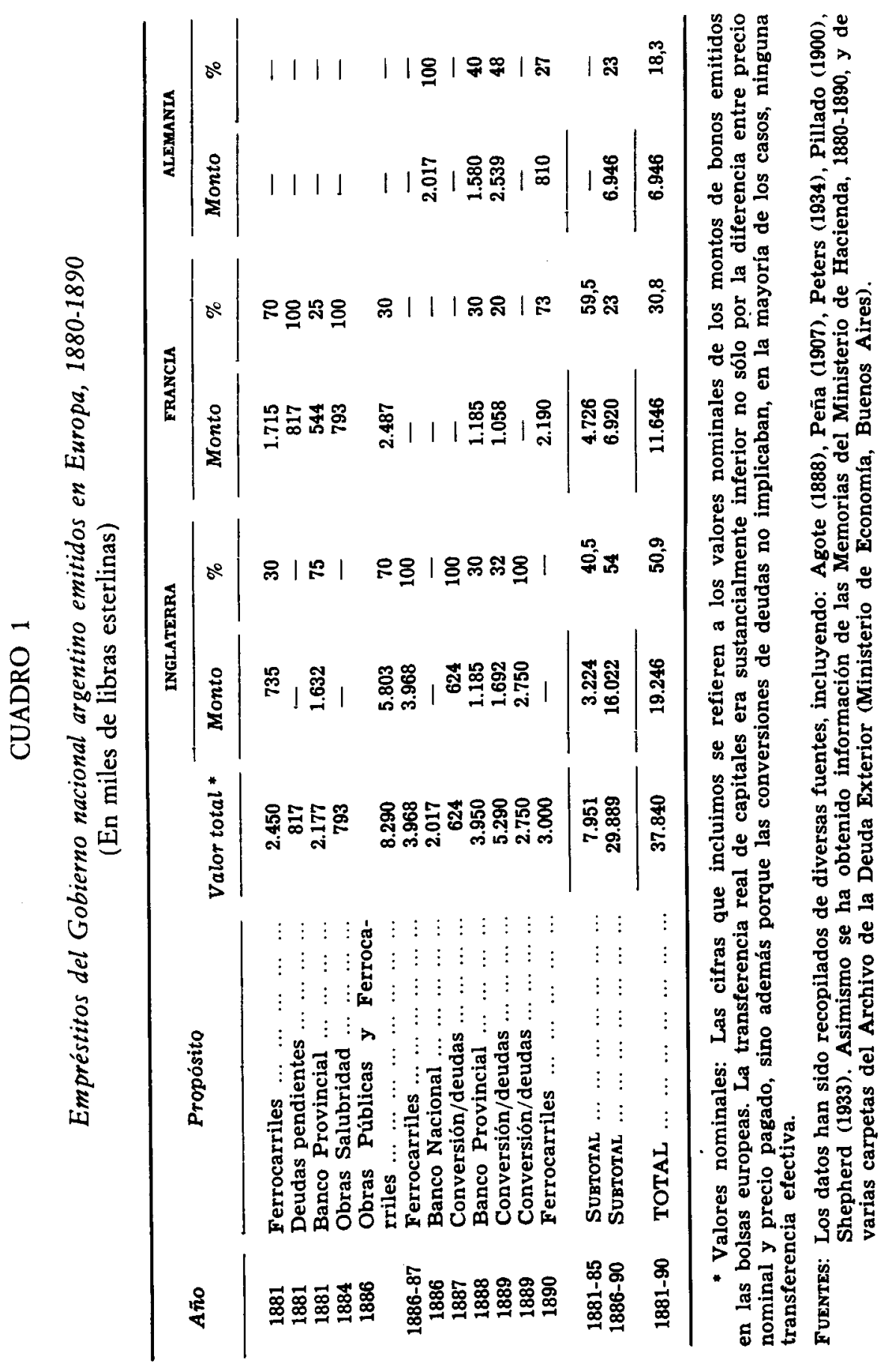




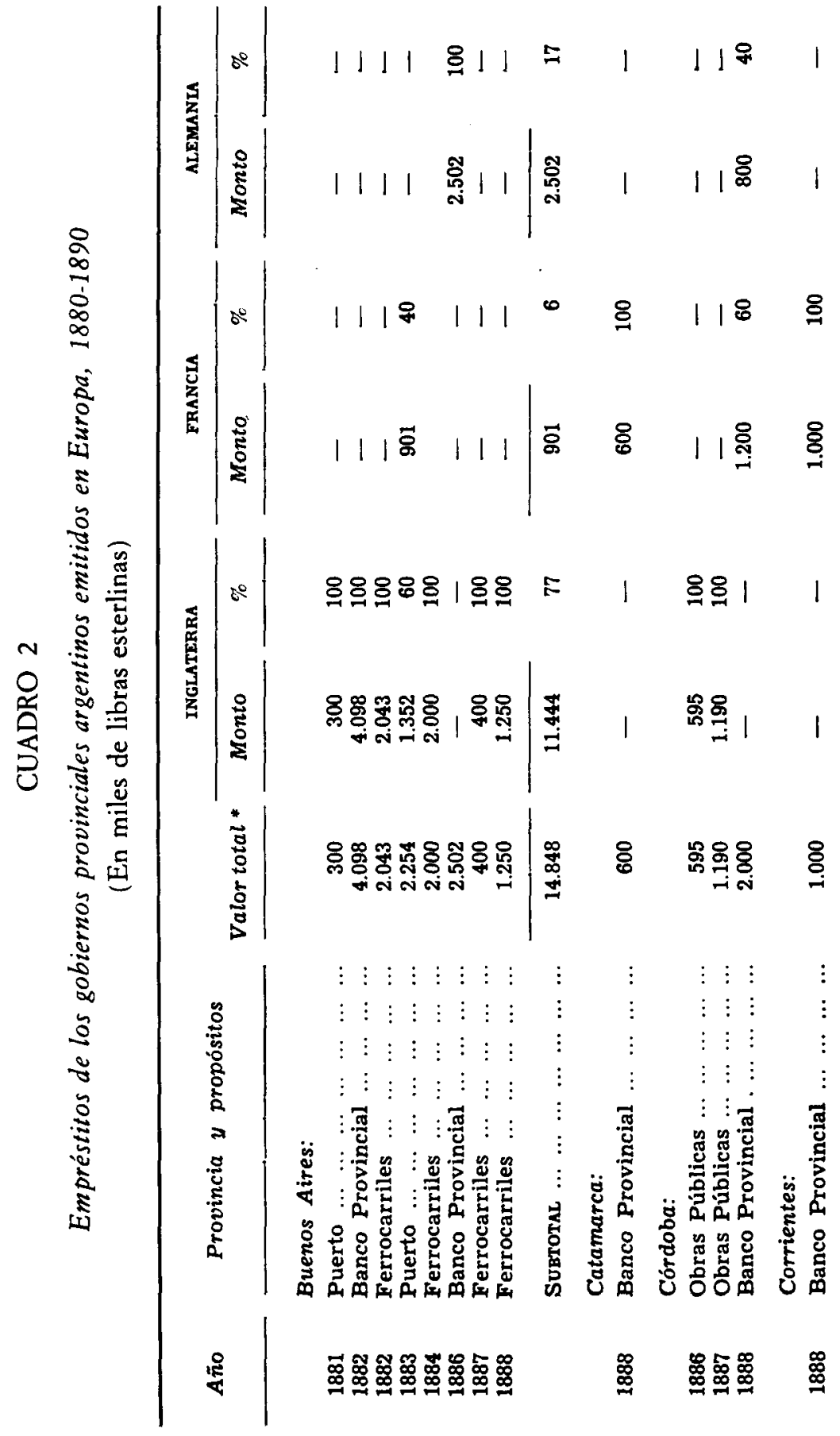




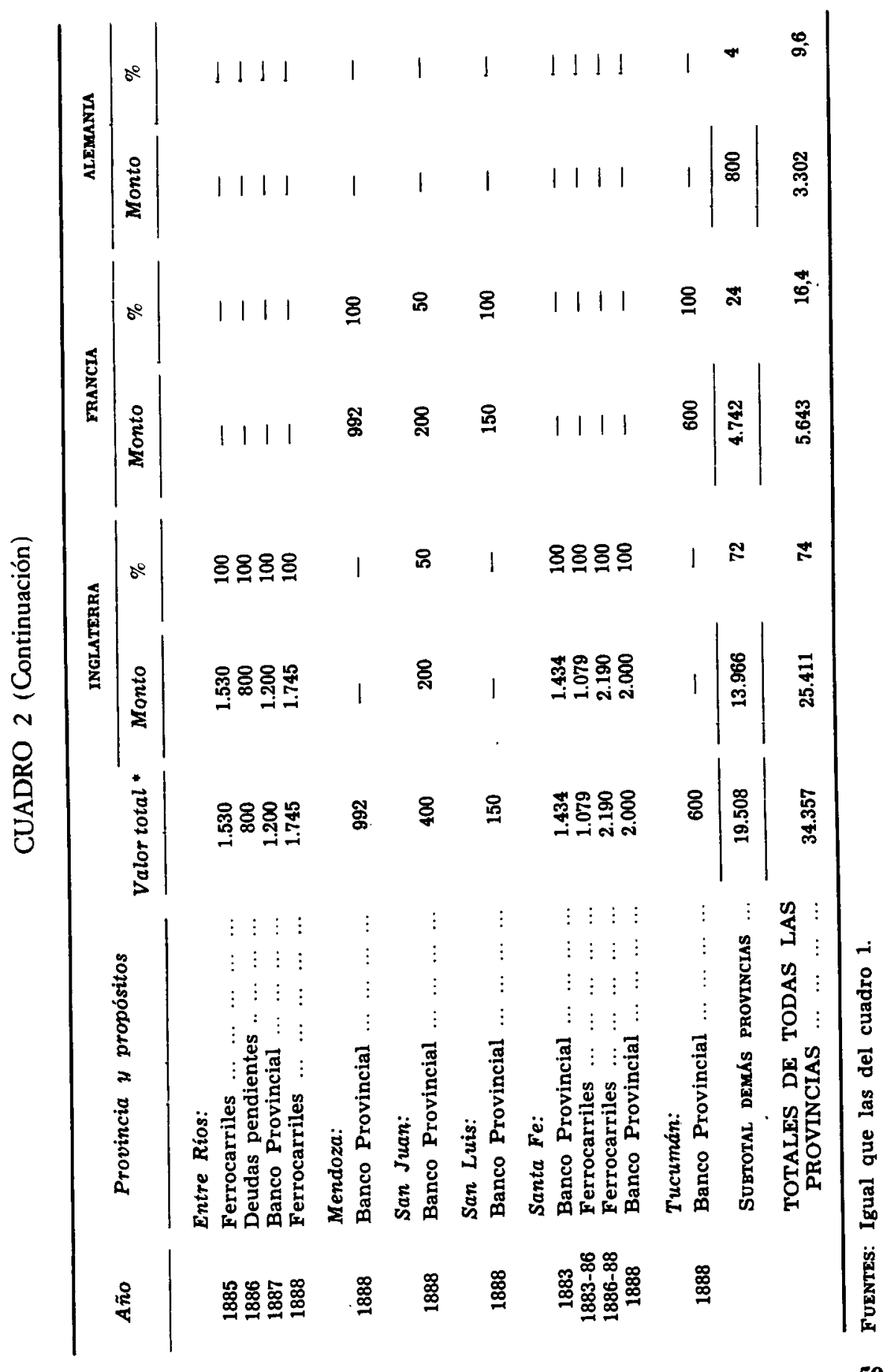


los mercados financieros provinciales, como Lyon, que revelaba la sorprendente capacidad del capitalismo en recuperarse de los efectos de la guerra de 1870 y de la crisis de 1873 . No obstante, los inversores galos habían sufrido pérdidas cuantiosas al demorarse (o suspenderse) los pagos sobre los grandes empréstitos españoles, turcos y egipcios, en los que habían participado de manera preeminente. Como señala Cameron, a partir de estas fechas, los inversores franceses comenzaron a abandonar las operaciones en el sur de Europa y Medio Oriente en favor de nuevas regiones ${ }^{21}$. A primera vista, América Latina podría parecer un campo propicio para la inversión, pero aquí también sufrieron pérdidas con los empréstitos franceses para México $(1864,65)$, Perú $(1869,70,72)$ y Honduras $(1869)$, ya que los gobiernos de estos países habían dejado de pagar los intereses y la amortización hacía varios años. Solamente Argentina parecía ser un riesgo seguro en 1880 y, por ello, las más prestigiosas firmas financieras de París no dudaron en ofrecer sus servicios a los ministros de Finanzas de Buenos Aires.

A pesar del estallido de la crisis bancaria de 1882 que se desató en París, estas poderosas casas bancarias continuaron intentando realizar nuevos negocios bursátiles con los títulos rioplatenses. Pero tal estrategia no constituía ahora una muestra de la prosperidad de la economía francesa, sino más bien lo contrario: las condiciones deprimidas de la actividad financiera interna de Francia hacían atractivo buscar algunos negocios rentables en el exterior.

En la práctica, el nivel de ganancias que podían obtener los banqueros e inversores franceses mediante la participación en empréstitos argentinos era sumamente alto. En el caso del préstamo ferroviario de 1881, por ejemplo, el «margen de utilidad» de los bancos emisores (que consistía de la diferencia entre el precio pagado al Gobierno y el precio de venta a los inversores) alcanzó el 9 por 100 - una cifra extremadamente alta-, y en varias operaciones posteriores los financieros siguieron disfrutando de ganancias similares. A su vez, los rentistas que adquirieron los títulos argentinos se vieron atraídos por las altas tasas de interés: más del 7 por 100 anual en términos reales; las tasas que pagaban los bonos del Gobierno francés, en contraste, no superaban el 4 por 100 durante el decenio de $1880-90^{22}$.

Desde 1886 y el retorno de una cierta prosperidad, la gran banca parisina volvió a expandir sus operaciones, pero ahora varias de las casas más poderosas dejaban de interesarse mayormente por los negocios argentinos. Ello se debió, al menos en parte, a una nueva y ambiciosa expansión hacia el este de Europa: desde esta época, las finanzas del Imperio ruso pasaban de manos de los banqueros alemanes a las de los mayores bancos franceses ${ }^{23}$. El

"Cameron (1861).

22 Homer (1963), pp. 223, 226-227.

23 Para detalles, véase Girault (1973), pp. 137-171. 
enorme volumen de los empréstitos rusos hizo que estos últimos dejasen de enfocar su atención sobre el Río de la Plata, dando lugar a que una amplia gama de casas bancarias, que podrían denominarse como secundarias, de varios centros financieros de Francia y Bélgica tomaran la delantera en los negocios sudamericanos ${ }^{24}$.

La alta rentabilidad implícita en las operaciones financieras argentinas, sin embargo, no fue el único factor que despertó el interés de los banqueros (grandes y chicos) e inversores franceses durante los años ochenta. Un elemento adicional, que suele menospreciarse, fue el peso adquirido por las relaciones mercantiles franco-argentinas. Para la economía francesa, el interés estratégico del Río de la Plata giraba en torno al papel que cumplían Argentina y Uruguay como proveedores de lanas ${ }^{25}$. Tan importante llegó a ser el volumen de este comercio que, durante el decenio de 1880-90, Francia se convirtió en el mayor comprador del total de las exportaciones argentinas. (Véase gráfico 1.)

La enorme importancia del comercio lanero, tanto para Argentina como para Francia, no debe separarse, por consiguiente, de ese otro fenómeno que era la intensificación de los flujos de capitales, especialmente de préstamos. Pues es razonable suponer que, tanto para los bancos involucrados como para los rentistas, resultaba más confiable invertir en países con los cuales se mantenía un nivel de intercambio intenso que con aquellos con los cuales no mantuviesen vínculos mercantiles significativos. En el caso argentino, sin embargo, se presentaría una situación aparentemente paradójica (de acuerdo con las teorías clásicas), ya que en esta instancia se daría el fenómeno de una exportación de capitales que no partía de una paralela exportación de mercancías, sino que, al contrario, corría pareja con las corrientes de importación ${ }^{26}$. Es decir, Francia exportaba capitales porque importaba lanas.

No obstante la afirmación anterior, también es cierto que los bancos franceses supieron aprovechar los empréstitos para promover la exportación de una cantidad nada despreciable de bienes de capital al Río de la Plata. Hasta 1875, la casi totalidad de las mercancías francesas que llegaban a Buenos

24 Estas firmas incluían primordialmente a casas como $L$. Cahen d'Anvers y Heine et Cie. - ambas de París-, pero también debe tenerse en cuenta el papel que jugaban las firmas de Bemberg. Portalis y Mallman, que pueden definirse como franco-argentinas, ya que tenían sendas oficinas en París y Buenos Aires. Tampoco debe descartarse la constante participación de los grandes bancos franceses -en particular el Comptoir d'Escompte y la Société Générale-, que siguieron vendiendo bonos argentinos en diversas plazas financieras del país a través de sus agentes.

25 Sobre el comercio lanero véase el excelente artículo de Sabato (1983).

26 Véanse los comentarios de Bouvier acerca de las relaciones entre las exportaciones de capitales $y$ de mercancías francesas a fines del siglo pasado en el último capitulo de Bouvier y Girault (1976). Para información general acerca de las inversiones francesas en América Latina, véase Mauro (1977). 
Aires, Rosario y otros puertos de la región consistían en bienes de consumo y de lujo: vinos, licores, textiles de seda y de lana, mueblería, etc. Pero posteriormente, y especialmente desde 1880 , el volumen de productos de la industria pesada francesa - rieles de acero, locomotoras, vagones ferroviarios, alambrado y maquinaria para ingenios azucareros- aumentó sustancialmente. Ello estaba relacionado directa o indirectamente con los flujos de capital, y en particular con los empréstitos de 1881,1885 y 1890 otorgados para financiar el ferrocarril estatal llamado "central Norte», que se extendió de la ciudad de Córdoba hasta Tucumán y Jujuy. Varias fuertes empresas industriales francesas estaban interesadas en este negocio. La compañía metalúrgica de Schneider-Creusot, por ejemplo, que ya había comenzado a exportar rieles y vagones a Argentina hacía algunos años, manifestó sus deseos de obtener nuevos contratos ${ }^{27}$. Por otra parte, diversas firmas francesas fabricantes de maquinaria para ingenios y de otro equipo pesado (como las de Decauville et Cie. y Fives-Lille, de París) tenían interés en consolidar su control del mercado para tales productos en la provincia azucarera de Tucumán, donde ya habían logrado introducirse desde fines de los años de $1870^{28}$.

Una faceta particularmente reveladora de este tipo de vinculación mercantil-financiera se descubre en el papel que cumplieron dos importantes firmas intermediarias de Buenos Aires, Bemberg y Cía. y Portalis Frères y Cía. El fundador de la primera, Otto Bemberg, se había radicado en el Río de la Plata desde mediados de los años cincuenta, operando como exportador de lanas e importador de mercancías francesas. Desde 1880, Bemberg actuaba como intermediario entre la banca parisina y el Gobierno argentino en la mayoría de los empréstitos nacionales y provinciales que se emitieron en Francia. Además de fungir como representante de los sindicatos bancarios de París, servía como agente local de firmas industriales como Schneider ${ }^{29}$. Un papel similar lo desempeñó la firma de los Portalis, estando fuertemente involucrada en el negocio azucarero, participando en varios empréstitos externos y actuando como agente de las empresas Fives-Lille y Decauville. En los años 1888-89, por otra parte, tanto Portalis como Bemberg participaron en varias empresas constructoras de ferrocarriles en las provincias de Santa $\mathrm{Fe}$ y Córdoba ${ }^{30}$.

El rol de estos intermediarios, por consiguiente, fue crítico para la im-

27 Para información sobre las exportaciones de Schneider-Creusto a Argentina, véanse Memoria del Ministerio del Interior (1880), p. LXXVII (1881), p. XXIV, y Zalduendo (1975), pp. 276, 408 y 413.

${ }^{28}$ Guy (1980), pp. 48-49.

29 Para algunos datos biográficos acerca de Bemberg, véanse Marichal (1976) y Arnoux (1977). Para datos sobre el papel de Bemberg en el financiamiento de varios gobiernos provinciales argentinos en 1886-1889, véase Lorini (1910), volumen II, pp. 238-243.

${ }^{3}$ Para información acerca de Portalis Freres, véase Arnoux (1977), pp. 86 y 95. 
plementación exitosa de las políticas de expansión francesa, tanto a nivel financiero como en el plano comercial. Sin embargo, no deben exagerarse los logros de la banca parisina y de sus aliados, pues en la práctica nunca lograron ejercer un control preponderante de los flujos internacionales de capitales entre el Río de la Plata y los centros europeos. Su éxito fue en cierto sentido mayor en los primeros años de los ochenta, pero durante el último tercio del decenio los financieros franceses se vieron en peligro de ser marginados no sólo por sus antiguos rivales, la banca británica, sino, asimismo, por una nueva fuerza en los mercados financieros internacionales: los bancos alemanes.

\section{Los bancos alemanes y los empréstitos argentinos}

La participación de la banca alemana en las finanzas internacionales de Argentina fue más tardía que la francesa $y$, por supuesto, que la inglesa. Pero, en los cuatro años que duró la breve y agitada presidencia de Juárez Celman (1886-1890), las firmas alemanas alcanzaron una posición nada desdeñable en la negociación y colocación de los principales empréstitos del Gobierno nacional y en algunas operaciones provinciales. Concretamente, durante este período (1886-90) los bancos germanos fueron responsables de un 23 por 100 del total de títulos del Gobierno nacional vendidos en Europa. (Véase cuadro 2.)

En realidad, las primeras iniciativas para conseguir la participación de los grandes bancos de Berlín en los negocios rioplatenses fueron tomadas por el Gobierno argentino. En 1885, Carlos Pellegrini, agente financiero de Roca en Europa, propuso la apertura de negociaciones con los financieros alemanes en un sindicato conjunto con la banca francesa e inglesa ${ }^{31}$. Pero la sugerencia no fue puesta en práctica, aparentemente debido a la oposición de las poderosas casas parisinas. No obstante, al poco tiempo, las renombradas firmas berlinesas del Deutsche Bank y de Mendelsohn fueron contactadas por un representante del Banco de la Provincia de Buenos Aires, quien les ofreció la posibilidad de emitir un préstamo externo para esa institución estatal. Los banqueros aceptaron apresuradamente, ya que la operación virtualmente les garantizaba un alto margen de ganancias, debido al bajo precio que estaban obligados a pagar al gobierno provincial por los bonos ${ }^{32}$. Al año siguiente, la firma bonaerense de Ernesto Tornquist y Cía. gestionó un empréstito del Gobierno nacional ante el Disconto Bank de Berlín y a partir de ese mo-

${ }^{31}$ Véase la nota 13.

32 El precio que pagaron los bancos al Gobierno de Buenos Aires fue de 75 , pero pudieron venderlos en las bolsas alemanas a 81. Además, los bancos cobraron una alta comisión por sus servicios del 2,5 por 100. Véanse Shepherd (1913), página 10, y Agote (1887), vol. IV, p. 48. 
mento la venta de bonos argentinos se multiplicó en los mercados de capitales alemanes ${ }^{33}$.

Para lograr una exitosa colocación de los bonos argentinos en los diversos mercados bursátiles de Alemania, los bancos Disconto y Deutsche organizaron amplios sindicatos que incluían, asimismo, al Darmstadter Bank, a las prestigiosas firmas privadas de los Oppenheim, de Colonia, y de M. A. Rothschild, de Frankfort, y varias casas bancarias de Hamburgo. En algunos casos, el respectivo sindicato alemán se encargó por cuenta propia de la totalidad de los títulos ofrecidos en venta, pero en otras ocasiones se colaboraba con otros sindicatos de bancos - franceses e ingleses-, adjudicándose el porcentaje de bonos por grupo bancario en base a una serie de acuerdos previos negociados con el Gobierno argentino ${ }^{34}$. En resumidas cuentas, era evidente que si bien los banqueros alemanes demostraron estar dispuestos a participar activamente en las finanzas internacionales, ello no implicaba que pudiesen operar en forma totalmente independiente de los demás centros financieros europeos. La competición y la colaboración eran dos caras de una misma moneda; compitiendo, el sindicato germano aspiraba a conseguir un fuerte porcentaje de los negocios rioplatenses; colaborando con otros grupos europeos, esperaba garantizar que la emisión -en su conjunto- fuese exitosa $y$, por ende, que tuviese un efecto positivo sobre la cotización de los bonos en las Bolsas de Berlín, Frankfort, Hamburgo y mercados secundarios.

$\mathrm{Si}$ bien se ha sugerido que una de las principales razones que instaba a los banqueros alemanes a participar en los empréstitos sudamericanos consistía en las altas tasas de ganancias que podían obtenerse mediante la venta de los bonos, ello no aclara cuáles podían sobre los móviles de los inversores compradores, aun cuando es claro que las tasas de interés reales que pagaban los títulos argentinos eran bastante altas. Tal problema requiere, al menos, unos breves comentarios acerca de la evolución general de los mercados bursátiles alemanes y la predisposición de los rentistas a efectuar inversiones en valores extranjeros.

En primer lugar, debe notarse que los años de 1886-89 fueron un período de extraordinario boom y especulación en las Bolsas germanas, al igual que en Londres y, en grado menor, en París. Por otra parte, fue precisamente durante esta etapa que tanto los bancos alemanes como los inversores individuales adquirieron una mayor cantidad de valores extranjeros que los que jamás habían comprado en el pasado $\mathrm{y}$, dicho sea de paso, una mayor pro-

33 Diouritch (1909), pp. 331-333.

34 Por ejemplo, en el gran empréstito de 5,2 millones de libras esterlinas de 1889 , el sindicato de bancos alemanes se responsabilizó por la venta del 48 por 100 de los bonos, el sindicato francés por el 20 por 100 y los bancos británicos de Baring Brothers y Murrieta por el 16 por 100 cada uno. Peña (1907), vol. I, páginas $476-484$ 
porción que la que habían de efectuar en decenios subsiguientes ${ }^{35}$. La euforia fue tan intensa que aproximadamente el 35 por 100 del total de los títulos vendidos en la Bolsa de Berlín entre 1886 y 1890 fueron bonos o acciones extranjeras ${ }^{36}$. Y ello a pesar de la notoria preferencia de los inversores alemanes por valores nacionales. Pero ¿por qué existía un interés específico y marcado por los bonos argentinos? Unicamente una investigación detallada de los archivos de los bancos alemanes - cuando fuese posible- y de la prensa financiera alemana contemporánea podría proporcionar una respuesta quizá definitiva. En todo caso, un factor que, sin duda, tuvo un impacto considerable sobre la preferencia de los inversores fue la decisión tomada, en 1887, por el canciller Bismark de romper la alianza político-militar con el Imperio ruso y, por ende, de reducir drásticamente los préstamos alemanes a ese país. Hasta entonces, los títulos rusos habían estado absorbiendo una fuerte cantidad de los fondos disponibles en la Bolsa de Berlín. La nueva decisión política influyó de manera significativa en canalizar los excedentes en nuevas direcciones, y más especialmente, en el caso de América Latina, hacia Argentina y México ${ }^{37}$.

Más allá de la coyuntura específicamente político-financiera, otra forma posible de interpretar la dinámica de las corrientes de capitales que comenzaron a afluir desde Alemania hacia el Río de la Plata consiste en analizar su relación con los flujos comerciales germano-argentinos. En otras palabras, es factible interpretar la participación en los empréstitos argentinos como parte de la campaña alemana para conquistar nuevos mercados para sus productos industriales en América del Sur. De hecho, las exportaciones alemanas hacia el Río de la Plata en los años ochenta aumentaron de manera sostenida, fenómeno que era complementado por la transformación de Alemania en el segundo comprador más importante de producțos argentinos, especialmente de cueros y lanas. (Véanse gráficos 1 y 2.)

Sin embargo, varios interrogantes se plantean con respecto a la vendadera naturaleza de la vinculación que pudiese haber existido entre la colocación de los empréstitos externos argentinos y la penetración de los mercados rioplatenses. Más concretamente, no resulta en verdad evidente que los bancos berlineses más fuertemente involucrados en los préstamos argentinos -el Disconto, Deutsche y Darmstadter- hayan coordinado, efectivamente, la venta de los bonos con un intento paralelo y conjunto de promover las exportaciones industriales alemanas. Es decir, no se ha encontrado mucha in-

35 Entre 1886 y 1890 el 35 por 100 del total de títulos vendidos en la Bolsa de Berlín eran valores extranjeros. Entre 1890 y 1905 la correspondiente cifra promedio era del 20 por 100 , y entre 1905 y 1914 del 15 por 100 . Whale (1930), p. 93.

36 Ibidem.

${ }^{3}$ Stern (1977), pp. 288 y 424-426. 


\section{GRAFICO 1}

Exportaciones argentinas con destino a Francia, Alemania, Inglaterra, $1880-1890$

(Valores absolutos) * (Millones de libras esterlinas)

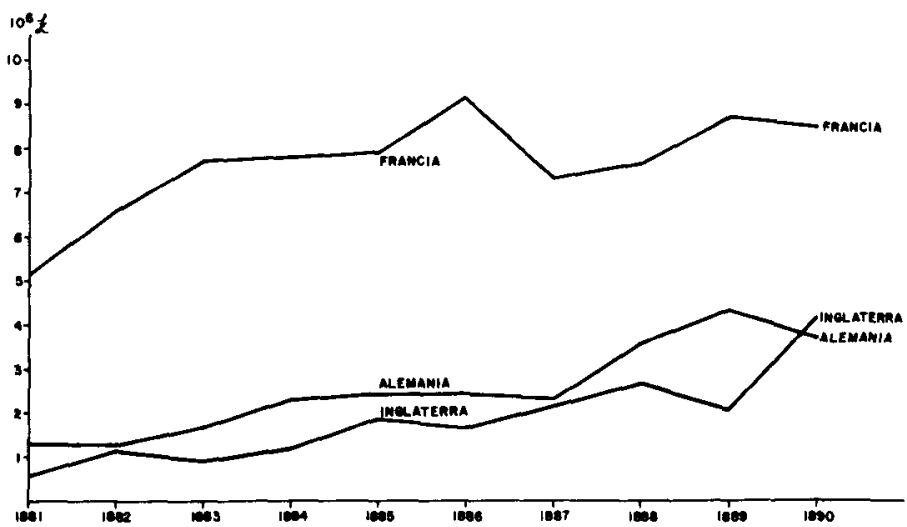

* Cifras europeas C.I.F.

Fugnte: Elaborado a base de datos en Vicente Vazquez Pressbo, Estadísticas históricas argentinas, Buenos Aires, Ed. Macchi, 2 vols., 1971 y 1976.

\section{GRAFICO 2}

Importaciones argentinas provenientes de Francia, Alemania e Inglaterra, $1880-1890$

(Valores absolutos) ${ }^{*}$ (Millones de libras esterlinas)

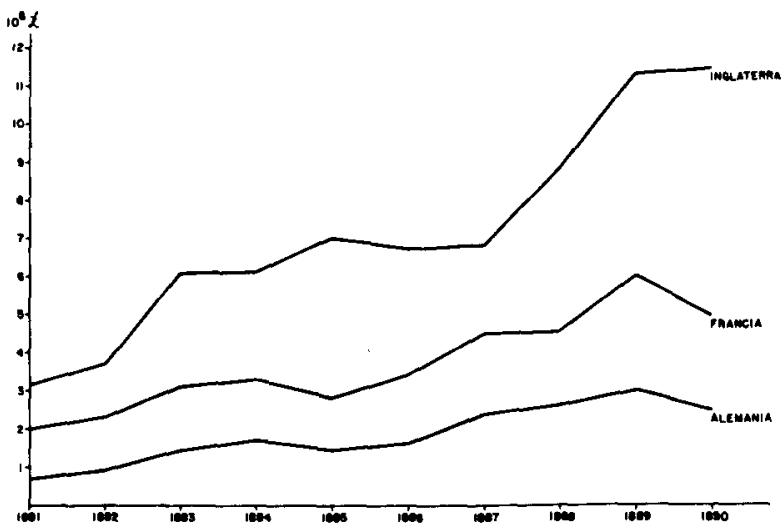

- Cifras argentinas C.I.F.

Fuentr: La misma que la del gráfico 1. 
formación que demuestre que los empréstitos en los que participaron los banqueros alemanes llegasen a ser préstamos «atados» que implicasen la venta de determinadas mercancías al Gobierno argentino o sus agencias. Existe abundante documentación acerca del impulso que estas mismas firmas - como bancos comerciales- dieron al comercio alemán. Pero las modalidades del crédito comercial eran sustancialmente distintas de aquellas implícitas en la negociación de los préstamos gubernamentales.

Ya desde principios de los años de 1870 , varios bancos alemanes se habian percatado de la importancia creciente del comercio con Argentina y comenzaron a ofrecer una serie de nuevas facilidades de créditos a exportadores e importadores ${ }^{38}$. Durante decenios, el comercio de los distintos Estados alemanes con el Río de la Plata había dependido en gran parte del papel complementario que cumplían numerosos intermediarios británicos, franceses y belgas, que proporcionaban servicios esenciales en las esferas del financiamiento, el comercio y la navegación. Las importaciones de lanas y cueros, por ejem. plo, fueron canalizadas primordialmente a través de puertos belgas, mientras que una porción de las exportaciones industriales alemanas fueron financiadas en buena medida por merchant banks ingleses que actuaban a través de una extensa red de corresponsales comerciales ${ }^{39}$.

Durante los años de 1870-80, algunos cambios comenzaron a efectuarse, especialmente a raíz del establecimiento de líneas regulares de vapores alemanes y de comunicaciones telegráficas entre Hamburgo y Buenos Aires. Ambos elementos contribuyeron poderosamente a estimular el comercio directo entre Alemania y Argentina. En reconocimiento de la creciente importancia de estas transacciones mercantiles, el Deutsche Bank decidió establecer una subsidiaria propia en Buenos Aires en el año de 1886, que se llamó el Banco Alemán Transatlántico ${ }^{40}$. Las operaciones financiadas por este último banco, sin embargo, poco o nada tenían que ver con los empréstitos estatales negociados por el Deutsche Bank. Tales préstamos estaban destinados a cumplir una serie de objetivos estrictamente financieros del Estado argentino y no implicaban contratos para obras públicas que hubiesen requerido la importación de bienes de capital. En esto puede notarse cierto contraste con el éxito de la banca francesa en obtener control de una serie de empréstitos para ferrocarriles estatales que sí produjeron contratos mercantiles complementarios.

3iouritch (1909), pp. 493-495.

39 Hasta fines de los años de 1870, Amberes sirvió como entrepot clave para el comercio sudamericano con varias regiones alemanas. En este sentido fue ejemplar el rol de la firma de E. Tornquist y Cla. (fundada originalmente por comerciantes de Amberes), que financiaba gran parte del comercio de exportación de lanas y cueros de Buenos Aires con destino a Alemania. Véanse Tilmant (1908), Korner (1956) y Newton (1977), pp. 15-16.

* Diouritch (1909), pp. 486-497. 
Los empréstitos en que participó el Disconto Bank tampoco fueron, a primera vista, muy productivos en el plano comercial. Pero había una diferencia importante. En el caso del Disconto, virtualmente todos los préstamos estatales fueron negociados a través de la casa bonaerense de Ernesto Tornquist y Cía. En sí mismas, las estrechas relaciones del Disconto con el banquero Tornquist - probablemente el financiero más influyente de la época, además de ser asociado íntimo de los poderosos políticos Roca y Pellegrinituvieron un impacto que posiblemente fuese más significativo para el comercio argentino-alemán que cualquiera de los empréstitos. Tornquist, por ejemplo, era el representante local de la poderosa firma alemana de acero y armamentos de Krupp y Cía, y fue a través de sus oficios que esta empresa obtuvo sus primeros contratos para la provisión de equipo militar y ferroviario requerido por el Estado argentino ${ }^{41}$. Tan útiles fueron los servicios prestados por la firma financiera de Buenos Aires que, a partir de 1889, el Disconto ingresó como socio «en comandita» de E. Tornquist y Cía. ${ }^{42}$.

En resumidas cuentas, resulta difícil, por el momento, formular una opinión concluyente acerca del impacto de los flujos de préstamos con respecto al comercio alemán en el Río de la Plata. En todo caso, pareciera que fue más indirecto que directo. Pero, desde el punto de vista estrictamente financiero, no cabe duda que la ofensiva de los bancos germanos representó un claro desafío a las otras potencias imperiales que operaban en Argentina en este período, y en especial para las poderosas casas financieras británicas, que se vieron obligadas a luchar denodadamente para mantener su supremacía.

\section{La competencia entre los banqueros británicos}

La participación de la banca británica en el financiamiento internacional argentino durante el decenio de 1880-90 tuvo, sin lugar a dudas, mayor importancia que la de cualquier otro país europeo. Ello se derivaba, en parte, de su ya larga experiencia en los negocios rioplatenses, que databa desde la época de la independencia ${ }^{43}$. A lo largo de cuatro décadas, varios merchant banks londinenses habían contribuido a financiar el comercio entre el Río de la Plata y Europa, pero, además, a partir de 1860 comenzaron a promover una serie de inversiones directas en la región, incluyendo el establecimiento

"Véanse referencias al rol de Krupp en Argentina en este periodo en Ferns (1968), p. 432; Sommi (1948), p. 58, y Schiff (1972), pp. 437 y 447.

42 La firma de Ernesto Tornquist fue en un principio una empresa mercantil, pero desde 1872 actuaba como Banco privado. Para información acerca de sus variadas e importantes actividades, véase Tornquis y Cía. (1924).

43 Sobre este tema véase abundante información en Ferns (1968) y Platt (1983). 
de varias empresas ferroviarias y tranviarias, un banco y una serie de compañías de tierras. Por otra parte, en los años 1865-73 las firmas financieras británicas alcanzaron a detentar un rol clave como prestamistas del Gobierno federal y de los gobiernos de las provincias de Buenos Aires, Santa Fe y Entre Ríos ${ }^{44}$.

En el año de 1880 , por consiguiente, los bancos ingleses estaban bien situados para ampliar sus intereses en la zona del Río de la Plata, precisamente en el momento en que allí comenzaba un período de muy rápido desarrollo económico. Las casas bancarias de Londres adoptaron una estrategia a dos puntas: por un lado, participaron activamente en la emisión de numerosos empréstitos nacionales y provinciales y, por otro lado, prestaban su concurso a una amplia gama de compañías privadas (de propiedad inglesa) que deseaban establecerse en la región.

En lo que se refiere a los préstamos estatales, los banqueros británicos participaron en la emisión de unos diez empréstitos nacionales y una veintena de empréstitos provinciales y municipales. Del total de bonos externos emitidos por el Estado argentino entre 1880 y 1890 , puede estimarse que aproximadamente un 59 por 100 del total de los títulos del Gobierno nacional y un 74 por 100 del total de los bonos provinciales se vendieron en Londres, mediante la intervención de tales casas bancarias. (Véanse cuadros 1 y 2.) Sumando los totales nominales de los fondos estatales y de los fondos invertidos por compañías inglesas, se llega a una cifra global de 133 millones de libras esterlinas transferidas a Argentina entre 1880 y $1890^{45}$.

Para numerosos observadores contemporáneos, tal movimiento de fondos fue tan abultado que contribuyó de manera decisiva a generar el boom especulativo que tuvo lugar en la Bolsa de Londres a fines de los años ochenta $y$, por ende, al estallido de la crisis de 1890. Después de todo, había que tener en cuenta que Argentina, efectivamente, absorbió el 59 por 100 del total de las inversiones de cartera británicas para América Latina durante el período ${ }^{46}$. Tal enfoque regional, sin embargo, no dejaría traslucir el hecho de que había otras zonas geográficas que recibieron todavía mayores cantidades de fondos. En particular, debía remarcarse que dos países con características bastante similares a las de Argentina, Estados Unidos y Australia, atrajeron flujos de capital sustancialmente superiores. (Véase gráfico 3.) Es más, podría afirmarse que la emisión de los valores argentinos no se hizo sentir

" La información básica acerca de estos préstamos se encuentra en Peters (1934), Agote (1887) y Peña (1907).

" Estas son cifras aproximativas basadas en nuestra propia información y la de Williams (1920), pp. 46-47, 104. Sin embargo, no se incluye información aquí acerca de las emisiones de cédulas hipotecarias.

* Cálculo basado en datos de Simon (1968), p. 40, y los datos de Simon recopilados por Stone (1972). 


\section{GRAFICO 3}

Bonos y títulos norteamericanos, australianos y argentinos como porcentaje del total de valores extranjeros vendidos en la Bolsa de Londres, 1880-1890

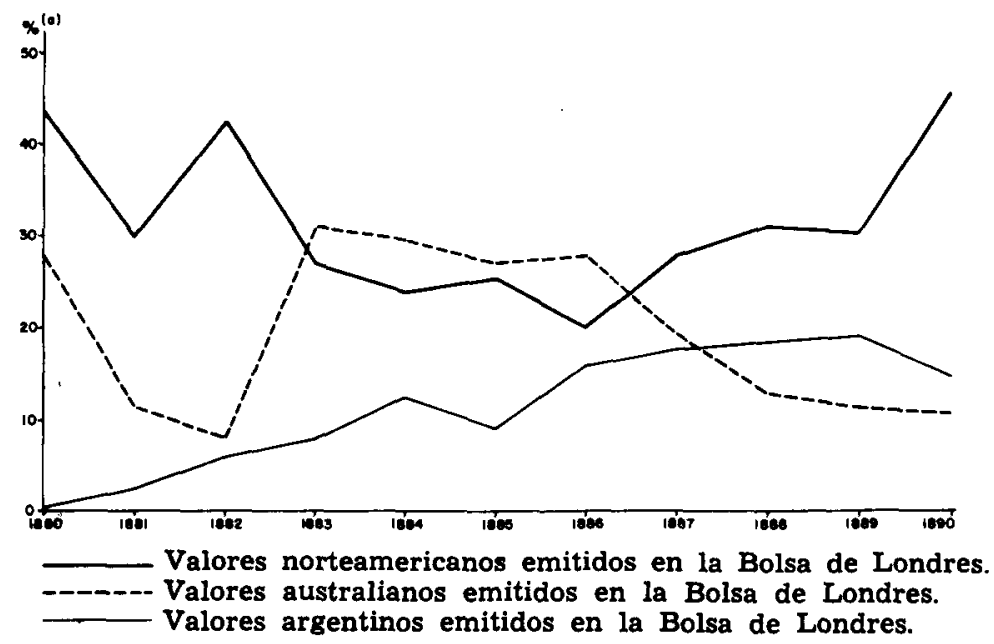

(a) Las cifras de la columna vertical representan el porcentaje del total de valores extranjeros vendidos en la Bolsa de Londres.

Fuente: Elaboración de cuadro basado en las cifras que se encuentran en Matthew Simon (1968) y Stone (1972).

con vendadera fuerza hasta los años 86-89, y aun entonces ejerció una influencia bastante inferior a la que tuvo la venta de acciones y bonos de los ferrocarriles norteamericanos, valores siempre preferidos por el público inversor inglés.

En todo caso, el creciente volumen de las transacciones financieras efectuadas con el Río de la Plata era tal que ya no podía ser monopolizado por una o dos casas bancarias inglesas. Ello contrastaba con la situación reinante en los años de 1865-73, cuando dos firmas, las de Baring y Murrieta, habían mantenido un control virtualmente exclusivo sobre los empréstitos argentinos. Desde 1880 , en cambio, se presentaron rápidamente a la lid otras diversas empresas bancarias, como las de Morton-Rose, J. S. Morgan, Stern Brothers, L. Cohen and Sons, Glyn-Mills, etc. Al respecto, conviene tener presente que estas casas no solían actuar de consuno en la emisión de los empréstitos estatales - como solía ser la costumbre entre los banqueros franceses y alemanes-, sino que actuaban de forma bastante más independiente. En sí, la 
autonomía de cada merchant bank británico contribuía de forma acentuada e inevitable a intensificar la competición entre ellos y a estimular el grado de actividad especulativa.

Claro está, la posibilidad de actuar exitosamente en forma individual era, en gran medida, resultado de la ventaja de trabajar en el mayor mercado mundial de capitales. Pues a la Bolsa de Londres acudían no sólo los inversores ingleses, sino, además, los capitalistas de un gran número de países adicionales, lo cual aumentaba la disponibilidad de fondos de forma extraordinaria ${ }^{47}$. A ello habría que agregar que, para movilizar tales recursos, los bancos contaban con el importante auxilio de determinados órganos de la prensa financiera, en tanto que éstos ejercían una gran influencia sobre la masa de los inversores. En el caso de las operaciones argentinas, por ejemplo, el prestigioso periódico denominado Money Market Review no cesó en apoyar a las firmas de Baring y Murrieta en sus diversas iniciativas. El objetivo de estimular la especulación era manifiesto, como lo indica el siguiente texto de principios de 1887:

«Ha sido un hecho reconocido en los últimos años que no existe un campo mejor o más remunerativo para la inversión del capital británico que aquel ofrecido por la República Argentina» ${ }^{48}$.

O éste de 1889:

«Aun en este momento, todo aquel inversor que desea obtener 4 ó 5 por 100 de intereses sobre capital (una cosa cada día más difícil de lograr) no puede hacer un mejor negocio que invertir en una selección de bonos estatales y ferroviarios argentinos, añadiendo quizá unos cuantos valores brasileños y chilenos» ${ }^{49}$.

En cambio, otros periódicos, como el London Times (que se decía más vinculado a la poderosa firma de N. M. Rothschild and Sons), tendían a adoptar posiciones mucho más críticas hacia las transacciones argentinas, prestando su apoyo a las inversiones en otros países. Las luchas entre los bancos se reflejaban, por lo tanto, en las posiciones encontradas de los diferentes periódicos londinenses, alcanzando un grado de virulencia particularmente agudo en las etapas de mayor agitación especulativa.

Que la competencia haya llegado a ser sumamente intensa, sin embargo, no implicaba que no existiera una cierta división de tareas entre los múltiples

" Sobre la concurrencia de inversores no británicos a la Bolsa de Londres desde mediados del siglo, véase Platt (1980), pp. 2, 3 y 6 .

Money Market Review, 30 de abril 1887, p. 752.

Money Market Review, 13 de abril 1889, p. 812. 
bancos británicos operando en Argentina, división que se establecía en base a ciertas "esferas de influencia» informal que cada uno se adjudicaba. La casa de Baring Brothers, por ejemplo, se encargaba habitualmente de la emisión de los mayores empréstitos del Gobierno nacional, frecuentemente encabezando sindicatos internacionales para ese propósito. Pero Baring's tenía, asimismo, cierta predilección por los préstamos del gobierno provincial de Buenos Aires y aquellos negocios vinculados a la modernización de la capital, conducta que eventualmente le llevaría a sobrecargarse de títulos argentinos ${ }^{50}$.

La prestigiosa firma anglo-española de Cristóbal Murrieta and Co., por su parte, participó en un número casi equivalente de empréstitos nacionales, pero siempre estuvo particularmente interesada en aquellos préstamos ligados al financiamiento del gran ferrocarril estatal "Central Norte». Esta actitud estaba fundada en motivos económicos muy precisos, pues su presencia en estas operaciones le permitió participar en la adjudicación de lucrativos contratos de compra de equipos y materiales importados para dicha empresa. Nada extrañamente, Murrieta simultáneamente se dedicaba al financiamiento de los gobiernos y ferrocarriles estatales de las provincias de Santa Fe y Entre Ríos ${ }^{51}$.

La cosmopolita banca anglo-americana de Morton-Rose, en cambio, adoptó una estrategia algo menos ambiciosa que la de Baring y Murrieta, ya que no participó en los grandẹs empréstitos nacionales. Más concretamente, Morton-Rose se limitó fundamentalmente a la emisión de unos cinco empréstitos destinados a apoyar la expansión del Ferrocarril Oeste de la Provincia de Buenos Aires. Pero aquí también el control sobre los flujos de financiamiento implicaba la posibilidad de contar con un porcentaje de los negocios derivados de la compra de equipo para esta gran y muy rentable compañía estatal ${ }^{52}$.

Por último, en lo que se refería al financiamiento de los demás gobiernos provinciales y de los gobiernos municipales, puede notarse que, por lo general, se encargaban de sus empréstitos una serie de firmas financieras londinenses algo menos conocidas o poderosas que las mencionadas anteriormente: entre estas casas menores se contaban, por ejemplo, las de L. Cohen and Sons, A. Rueffer and Sons y Heinemann and Co. Tales compañías no gozaban de suficiente prestigio para poder negociar exitosamente con el Gobierno

so Para información acerca de Baring Brothers hasta 1870, véanse Hidy (1949) y Platt (1983). Para su papel en 1890, véase Ford (1956).

"Para información acerca de las operaciones de Murrieta, véanse Memoria (Departamento de Hacienda de la provincia de Buenos Aires) (1870), pp. 108-137; Agote (1887), vol. IV, pp. 54-55; Mulhall (1885), pp. 62, 421-422; Zalduendo (1975), páginas 285, 297, 411.

${ }^{32}$ Morton-Rose llevaba a cabo similares operaciones con los ferrocarriles canadienses. Véase Naylor (1975), pp. 68-69. 
nacional argentino, pero, en cambio, eran los interlocutores idóneos para los gobernadores provinciales, quienes estaban dispuestos a ofrecerles atractivas comisiones si lograban introducir sus bonos en los mercados europeos. La colocación de 600.000 libras esterlinas en bonos del gobierno provincial de Córdoba - para citar un caso típico- no requería de los servicios de una casa tan renombrada como Baring, por lo que pudo ser emprendida satisfactoriamente por la más pequeña de L. Cohen and Sons. Aun así, debe observarse que esta última firma tenía los contactos internacionales necesarios para poder organizar un minisindicato internacional (incluyendo varios bancos alemanes y franceses) para obtener una colocación satisfactoria ${ }^{53}$.

La competencia entre los distintos banqueros de Londres era intensa, por lo tanto, y se fue acentuando en la medida en que el número de empréstitos argentinos fue multiplicándose, especialmente en los años $86-89^{54}$. Luchaban entre sí para obtener una cuota parcial o total del respectivo empréstito y, al mismo tiempo, batallaban contra aquellos rivales del continente europeo que intentaban arrebatarles tales negociones sudamericanos. No obstante, en numerosas ocasiones los bancos ingleses no tuvieron otra alternativa que forjar determinadas alianzas que pudiesen garantizar la emisión y evitar el fracaso. En otras palabras, las mismas características del negocio de la emisión de los empréstitos extranjeros implicaba que, a pesar de la fuerte rivalidad, también existía un fluctuante nivel de colaboración, especialmente a la hora de lanzar los mayores préstamos o, alternativamente, cuando había necesidad de colocar con rapidez los valores de ciertas entidades estatales poco conocidas en los mercados europeos.

Pero aun en estos últimos casos la colaboración entre los bancos ingleses no solía ser particularmente estrecha, por lo menos si lo comparamos con sus homólogos franceses y alemanes. Mientras que los mercbant banks británicos participaban esencialmente a título individual en un sindicato internacional determinado, las firmas continentales solían presentarse como grupos mucho más unidos. Por ejemplo, en el gran empréstito de conversión de 1889, dos sólidos y compactos sindicatos de bancos alemanes y franceses participaron al lado de las firmas de Baring y Murrieta, que participaban de forma autónoma y sin contar, aparentemente, con el apoyo de otras casas londinenses ${ }^{55}$.

Si bien la discusión precedente sugiere que los bancos británicos no operaban en bloque, sino de manera marcadamente individualista, cabe indagar

s3 Pillado (1900), vol. I, p. 132.

54 La competencia fue impulsada enormemente por las concesiones ferroviarias argentinas en las que participaron muchas de estas casas bancarias. Véanse referencias en los artículos del Money Market Review, 30 de abril de 1887, 14 de mayo de 1887 y 10 de mayo de 1888 .

ss Véase su participación en el empréstito de 1889: Peña (1907), vol. I, páginas $437-450$. 
sobre otra problemática relacionada con la estrategia general de los mismos. Ello se refiere a la existencia (o no existencia) de un esfuerzo de tales firmas por vincular las operaciones financieras con las transacciones mercantiles. En otras palabras: ¿ hasta qué punto fue cierto que la banca británica realizó un esfuerzo sistemático por utilizar las exportaciones de capitales como vehículo para promover una expansión de las exportaciones de manufacturas inglesas?

Esta cuestión ha despertado el interés de numerosos economistas, marxistas y no marxistas. Para Rosa Luxemburgo, por ejemplo, el caso argentino de los años ochenta ofrecía una de las más claras ilustraciones de la estrecha relación entre exportación de capitales y exportación de bienes de capital británicos ${ }^{56}$. Este ejemplo histórico ofrecía a la famosa escritora y militante polaca una muestra palpable de su tesis acerca del rol que cumplían los empréstitos en la ampliación de los mercados en los países menos desarrollados, con lo cual se facilitaba la colocación de los excedentes de mercancías de las potencias imperiales. En cambio, para el historiador económico inglés S. B. Saul, la experiencia argentina demostraba que el financiamiento británico favorecía no exclusivamente a las exportaciones manufactureras inglesas, sino que alentaba en igual o mayor grado las exportaciones de otros países competidores, como Francia, Bélgica o los Estados Unidos, hacia el Río de la Plata ${ }^{\text {}}$. La emisión de empréstitos en Londres, por lo tanto, conducía a fomentar una serie de transacciones de carácter «multilateral».

Atacando el problema desde otros puntos de vista, los economistas J. H. Williams, A. G. Ford y M. Barrat Brown ofrecieron una serie de formulaciones e hipótesis distintas ${ }^{56}$. En lo que se refiere a una muestra estadística, los estudios de Ford son probablemente los más contundentes y tienden a corroborar las tesis de que los flujos de capital estimulaban una correspondiente corriente de mercancías inglesas hacia el Río de la Plata. Las respectivas curvas de emisiones de valores argentinos en la Bolsa londinense y de exportaciones de manufacturas británicas a Argentina corren paralelas, la primera precediendo a la segunda por uno o dos años ${ }^{59}$. En este sentido, y aunque parezca paradójico, los cuidadosos estudios del economista conservador inglés Ford tenderían a coincidir con las interpretaciones de Luxemburgo.

Debemos notar, sin embargo, que virtualmente toda la discusión que han emprendido los economistas ya mencionados con respecto al caso argentino se ha situado en el plano general $\multimap$ macro-, sin analizar con suficiente

* Luxemburgo (1967), pp. 329-330.

7 Saul (1960), pp. 72-79.

se Williams (1920), capítulos 11 y 12; Ford (1966), capítulos 7 y 8, y Barrat Brown (1974), pp. 173-175.

59 Ford (1971). 
detalle ni las características de las transacciones individuales - a nivel microni las estrategias específicas de los diferentes grupos de bancos que dirigían las operaciones bajo cuestión. Ya hemos indicado al principio del ensayo que virtualmente ningún autor ha prestado atención al papel de los bancos franceses o alemanes dentro de este contexto. Pero tampoco se ha estudiado con suficiente detenimiento la estrategia específica de los distintos bancos ingleses.

Aunque, en términos generales, la tesis de Ford pueda ser considerada como válida, citaremos un caso concreto que tiende a apuntalar la opinión contraria de Saul, en el sentido de que la banca británica estimulaba - consciente $o$ inconscientemente- un alto grado de transferencias multilaterales. Nos referimos específicamente al papel de la banca Morton-Rose en el financiamiento del Ferrocarril Oeste de la Provincia de Buenos Aires ${ }^{60}$. El ejemplo es interesante por dos motivos. En primer lugar, porque Morton-Rose era - como gran número de los merchant banks de Londres- una firma eminentemente cosmopolita, con lazos internacionales muy diversos. (Lo cual hace pensar sobre el significado que tenía el hecho de que buena parte de los capitales que eran movilizados en la Bolsa de Londres lo fueron por firmas que no eran ciento por ciento británicas.) $Y$, en segundo lugar, porque el estudio de estas transacciones financiero-mercantiles demuestra cómo los directores de la mayor empresa estatal argentina de la época pudieron formular un «paquete» financiero-comercial-tecnológico que proporcionaba las mayores ventajas a la compañía mediante la combinación de varias operaciones simultáneas con empresas proveedoras de diferentes países. Es decir, el grado de sofisticación demostrado por los directores de este ferrocarril estatal sugiere que en la Argentina de 1880 existían, al menos, algunos administradores gubernamentales que tenían plena comprensión de cómo se podía lidiar con los problemas de la dependencia tecnológica y financiera.

Para poder efectuar un detallado análisis microeconómico de este tipo de compleja y multifacética transacción, centraremos nuestra atención en una operación financiera del año de 1882 y en los cuatro actores principales: 1) la agencia estatal que solicitó y recibió el préstamo -el Ferrocarril Oeste de la Provincia de Buenos Aires-; 2) la banca londinense de Morton-Rose and Co.; 3) el agente financiero local, la firma bonaerense de S. B. Hale y Cía.; 4) las compañías industriales extranjeras que fueron proveedoras de equipo.

Lo primero que debe subrayarse es el carácter algo excepcional del Ferrocarril Oeste, ya que esta empresa estatal era la compañia ferroviaria más rentable de Argentina desde su inicio, en 1857, hasta mediados de los años

- Se encuentra abundante información acerca del financiamiento éxterno del Ferrocarril Oeste en las Memorias del Departamento de Hacienda de la provincia de Buenos Aires y en Agote (1888). 
de $1880^{61}$. En sus primeros años de existencia había sido financiada fundamentalmente por el Banco de la Provincia de Buenos Aires, pero debido a las necesidades crecientes de obtener equipo moderno importado - rieles, locomotoras, etc.- la firma se vinculó desde 1870 con los bancos de C. de Murrieta y Baring Brothers ${ }^{62}$. Estos facilitaron numerosas operaciones financieras a corto y largo plazo para que el ferrocarril pudiese ir extendiendo sus vías a través de las zonas más prósperas del centro y oeste de la pampa húmeda. Desde 1882, los gerentes del ferrocarril decidieron que para obtener apoyo adicional se estaba en condiciones de intentar la venta de bonos de la propia empresa en los mercados bursátiles europeos, sin tener que recurrir al gobierno provincial como sostenedor de la operación. En otras palabras, se estimaba que la compañía estatal ya era suficientemente solvente por sí misma como para poder atraer el interés de los inversores extranjeros. La transacción a efectuarse consistía en la venta de dos millones de libras esterlinas en bonos ferroviarios, que pagarían un 6 por 100 de interés anualmente. Con tales fondos se planeaba adquirir suficiente equipo como para cumplir con las metas de expansión de la empresa.

Los directores del ferrocarril pronto se pusieron en contacto con la casa bonaerense de Samuel Hale y Cía. (de origen norteamericano), que fungía como agente local de la banca de Morgan-Rose, así como de varias firmas industriales extranjeras. Hale contactó a la casa bancaria londinense, que aceptó encargarse de la colocación de los bonos ferroviarios, en una operación que se llevaría a cabo en alianza con la firma financiera hermana de Morton, Bliss de Nueva York ${ }^{63}$. En la práctica, casi todos los bonos se vendieron en Londres, pero el contacto norteamericano tuvo importancia a otros niveles.

Al respecto, es conveniente tener en cuenta que la casa de Morton-Rose tenía una larga experiencia en el financiamiento de ferrocarriles, no sólo en Estados Unidos, sino, asimismo, en Canadá. De hecho, John Rose -uno de los socios principales de la firma - era uno de los políticos y banqueros más poderosos de Canadá de la época ${ }^{4}$. Y, naturalmente, Rose tenía un amplio conocimiento acerca de cómo llevar a cabo el tipo de transacción multilateral que estamos analizando. En el caso de la construcción de los ferrocarriles canadienses, por ejemplo, era frecuente solicitar los fondos de capital de la Bolsa de Londres, pero importar el equipo pesado de Estados Unidos. La

61 Sobre la historia del Ferrocarril Oeste, véase Zalduendo (1975), pp. 265-285.

¿2 Información acerca de las operaciones con Murrieta en 1870 se encuentra en Memoria del Departamento de Hacienda de la provincia de Buenos Aires (1870), pp. 108-145.

${ }^{63}$ Charles Sanford, vicepresidente de S. B. Hale y Cía., viajó a Nueva York para promover la venta de los bonos, aunque aparentemente no tuvo mucho éxito. Drees (1922), pp. 180-182.

4 Sobre John Rose y su firma Morton-Rose véase Naylor (1975), pp. 68-69, 221. 
operación propuesta por el Ferrocarril Oeste de la Provincia de Buenos Aires se asemejaba mucho a este modelo.

Morton-Rose procedió a la venta de los bonos, lo cual se llevó a cabo exitosamente. Posteriormente, los administradores del Ferrocarril Oeste notificaron a sus agentes de compras que utilizaran las esterlinas para adquirir equipo de tres países diferentes: Estados Unidos, Francia y Bélgica. En primer lugar, S. B. Hale negoció con la empresa industrial estadounidense de Baldwin Locomotives la entrega de varias locomotoras. Seguidamente, otros agentes contactaron a la firma francesa de Schneider-Creusot para el suministro de rieles y adicionales locomotoras, y a varias compañías belgas para llenar un pedido de 1.500 vagones de carga y de pasajeros ${ }^{65}$.

En resumidas cuentas, los directores del Ferrocarril Oeste pudieron utilizar fondos de Inglaterra para obtener un conjunto variado de equipo moderno en otros países capitalistas. Evidentemente, aquí tenemos un claro ejemplo de lo que Saul denomina transferencias «multilaterales». La emisión del empréstito de 1882 en Londres, por consiguiente, no servía para estimular las exportaciones británicas, sino más bien las de sus competidores.

Claro está, no todas las transacciones financieras efectuadas por los bancos ingleses manifestaron este carácter multilateral, pues las cifras globales manejadas por Ford indican una correspondencia bastante estrecha entre flujos de capital y de mercancías de ese país. Pero el ejemplo citado debiera, al menos, ponernos en guardia contra la aceptación acrítica de las tesis de Luxemburgo y Ford.

Por otra parte, hay que tener presente que numerosos empréstitos argentinos no tenían una finalidad productiva -como podía ser la construcción de un ferrocarril-, sino que servían a fines que podrian ser considerados como estrictamente financieros. En las numerosas operaciones de "conversión» realizadas a fines de los años ochenta, por ejemplo, la participación de la banca británica ( $y$ europea) se vio limitada esencialmente a la venta y/o canje de bonos, sin que se desprendiera de estas transacciones ningún contrato para la adquisición de equipo importado ${ }^{66}$. Aun así, también es cierto que el control sobre tales empréstitos daba a los bancos extranjeros un poder considerable con respecto al manejo financiero del Estado argentino. Las consecuencias catastróficas de un endeudamiento externo excesivamente abultado se harían evidentes a partir de la crisis del 90 , y acentuarían en mayor grado que nunca el dominio de los capitales externos dentro de la economía nacional. Pero éstos son temas que necesariamente van más allá de los límites de este ensayo.

os Sobre las compras efectuadas, véase la Memoria del Ferrocarril Oeste anexa a la Memoria del Departamento de Hacienda de la provincia de Buenos Aires, 1882. 


\section{Conclusiones}

Para cerrar nuestra breve comparación de las estrategias implementadas por los distintos grupos bancarios europeos con respecto a las finanzas internacionales argentinas durante el decenio de $1880-90$, puede resultar útil sintetizar algunas de nuestras conclusiones generales.

En primer lugar, debe remarcarse que la internacionalización de la deuda argentina obedeció a una combinación de factores internos y externos. Por un lado, es evidente que las políticas adoptadas por el conjunto de las entidades estatales argentinas para obtener fondos en el extranjero se constituyeron en un «polo de atracción» para los inversores y banqueros europeos. Por otro lado, debe tenerse en cuenta que los años ochenta fueron una etapa de considerable acumulación de capital-dinero en las Bolsas europeas, que requerían de nuevas salidas hacia el exterior. Sin embargo, tales salidas no se efectuaban de manera constante, sino en una serie de olas fuertes pero cortas, impulsadas en gran medida por los niveles de actividad especulativa.

En los tres países industriales más avanzados de Europa - Inglaterra, Francia y Alemania-, los bancos de primera y segunda línea aprovecharon la coyuntura para canalizar fondos hacia América Latina, pero en especial hacia el Río de la Plata. Tal actividad concurrencial acentuó la magnitud de los flujos transatlánticos de capital, pero al mismo tiempo contribuyó a intensificar las crisis que se desataban al cerrarse la fase de auge. Ello tendió, por consiguiente, a imprimir una tendencia fuertemente cíclica, tanto a nivel de la evolución de las finanzas estatales como sobre el conjunto de la economía argentina.

Al analizar la formulación de las estrategias de expansión de los banqueros europeos, encontramos que se fueron dibujando distintas vertientes que respondían a la respectiva coyuntura financiera en cada país y a las diferentes modalidades adoptadas por cada banco o grupo bancario. En el caso francés, por ejemplo, la participación en los empréstitos argentinos fue particularmente intensa en los años de 1880-82 y 1887-89; al principio tomaron el liderazgo en tales transacciones varios de los bancos más poderosos de París, pero a fines de la década se hacía notar, asimismo, la participación de firmas financieras secundarias. La banca alemana, por su parte, no comenzó a intervenir en los empréstitos rioplatenses hasta los años de 1886.89 , pero actuó de forma algo más coordinada, formando sindicatos nacionales - de bancos grandes y chicos - para poder colocar los bonos en el conjunto de las plazas financieras de ese país. En contraste, los bancos ingleses adoptaron las modalidades más individualistas de acción. Ello se debió fundamentalmente a su acceso a mayores reservas de capital, que les permitió mantener un nivel de transferencias más constantes a lo largo del decenio de 1880-90, incluyendo 
no sólo préstamos para el Gobierno argentino, sino también un alto nivel de inversiones directas.

La rivalidad entre las más prestigiosas casas financieras de Londres y con los diversos bancos de Europa continental tendió a intensificarse progresivamente. Ello no era extraño dada la alta tasa de ganancias que proporcionaban las operaciones argentinas. No obstante, la rivalidad fue matizada en determinadas ocasiones por una tendencia a buscar la colaboración entre varios bancos o grupos bancarios ingleses, franceses y alemanes; tal entendimiento se hizo necesario para lograr la emisión de varios de los mayores empréstitos nacionales $y$, en menor grado, para ciertos empréstitos provinciales y municipales. Es algo dudoso suponer, sin embargo, que tal colaboración hava reducido efectivamente el nivel de competencia. Las alianzas transitorias entre los bancos de diferentes nacionalidades obedecía más bien al deseo común de impedir que la extraordinaria multiplicación de las transacciones financieras argentinas en las plazas europeas perdiese su impetu. Pues, en caso contrario, las olas especulativas podrian ser cortadas, produciendo una crisis financiera.

Por último, en lo que atañe a los intentos de la banca europea para articular la estrategia financiera con la mercantil, hemos observado que su implementación dependía del tipo de empréstito que era requerido por el Estado argentino. Aquellos préstamos destinados a la construcción de ferrocarriles estatales $u$ otras obras públicas implicaban, naturalmente, importantes contratos para la adquisición de equipo importado. En cambio, las operaciones orientadas hacia la conversión de deudas anteriores o hacia los bancos estatales no generaban directamente intercambios mercantiles de la misma índole. Al participar en el primer tipo de empréstito, era común que los banqueros europeos intentasen utilizar los fondos emitidos para estimular las exportaciones industriales de su respectivo país. Pero el éxito en plasmar tal estrategia fue desigual. Notamos ya en varias oportunidades que los banqueros parisinos tendieron a lograr sus objetivos en este sentido. Los bancos alemanes, en cambio, y a pesar de su acción unificada, tuvieron menos fortuna. Los merchant banks ingleses, por su parte, consiguieron impulsar las exportaciones industriales británicas, pero no de manera tan acentuada como quizá habría de esperarse, dada su notoria superioridad en el terreno estrictamente financiero. De hecho, un porcentaje significativo de los fondos levantados en la Bolsa londinense para financiar el desarrollo argentino contribuyeron a una fuerte transferencia «multilateral» de bienes de capital, incluyendo no sólo productos ingleses, sino, asimismo, franceses, belgas, alemanes y hasta estadounidenses, que fueron utilizados para la construcción de los ferrocarriles estatales y diversas obras públicas de Argentina en este período.

En resumidas palabras, la «internacionalización» de las finanzas argentinas 
fue un proceso complejo y contradictorio. Y ello no debe extrañarnos, ya que la ampliación de las relaciones capitalistas era, por su naturaleza misma, un fenómeno creador y destructor que provocaba nuevos conflictos dentro de la sociedad argentina, como entre las principales potencias imperiales con intereses crecientes en la zona del Río de la Plata. Esperamos, en todo caso, haber demostrado que el grado de rivalidad entre los distintos grupos de bancos británicos, franceses y alemanes que participaron en los empréstitos argentinos del decenio de 1880-90 era mucho más acentuado de lo que se suponía anteriormente. Pues la comprensión de este fenómeno, añadiríamos, constituye un factor fundamental para entender las diferentes modalidades de la dependencia financiera en la que el Estado argentino se vio, cada vez más profundamente, envuelto hacia finales del siglo pasado.

\section{BIBLIOGRAFIA}

Agore, Pedro (1881-1888): Informe del presidente del Crédito Público sobre la deuda pública, bancos $y$ emisiones de papel moneda, 5 vols., Buenos Aires.

ARNoux, Henri (1977): "Le role des français dans la fondation de l'industrie argertine a la fin du $\mathrm{xx}^{*}$ et debut du $\mathrm{xx}^{e}$ siècle", Cahiers des Ameriques Latines, número 16, 2.0 semestre, París, pp. 79-104.

Barrat Brown, Michael (1974): The Economics of Imperialism, Londres, Penguin. Bouvizr, Jean (1960): Etudes sur le Krach de l'Union Générale, 1878-1885, París, Presses Universitaires de France.

BouviER, Jean, y GIRAult, René (eds.) (1976): L'Imperialism Français d'avant 1914, París, Mouton.

Camaron, Rondo (1961): France and the Economic Development of Europe, 18001914, Princeton, Princeton University Press.

Cortes Conde, R., y Gazlo, E (1973): La formación de la Argentina moderna, Buenos Aires, Paidós.

DE GUERrico, Alberto (1886): Finanzas argentinas. Estudios e ideas sobre nuestros empréstitos externos, Buenos Aires-La Plata.

Departamento de Hacrenda (provincia de Buenos Aires) (1870-1873): Memoria, Buenos Aires.

Drourrtch, George (1909): L'Expansion des Banques Allemandes a l'Etranger, París.

DrEss, Charles (1922): Americans in Argentina, Buenos Aires.

Fens, Charles (1883): Compendium of the English and Foreign Funds, Debts and Revenues, Londres.

Ferns, H. (1968): Gran Bretaña y Argentina en el siglo XIX, Buenos Aires, SolarHachette.

Ford, A. G. (1956): "Argentina and the Crisis", Oxford Economic Papers, Oxford.

- (1966): El patrón oro: 1880-1914. Inglaterra y Argentina, Buenos Aires, Instituto Di Tella.

- (1971): "British investment in Argentina and Long Swings, 1880-1914", Journal of Economic History, vol. XXXI, núm. 3, pp. 650-663.

GrRault, René (1973): Emprunts russe et investissements français en Russie, 18871914, París, A. Colin.

Guy, Donna (1980): Argentine Sugar Politica: Tucuman and the Generation of Eighty, Arizona State University Press. 
HIDY, Ralph (1949): The House of Baring in American Trade and Finance, 17631861, Cambridge, Harvard University Press.

Hodge, John E. (1970): "Carlos Pellegrini and the Financial Crisis of 1890", Hispanic American Historical Review, 50:3, pp. 499-523.

Homer, Sydney (1963): A History of Interest Rates, New Brunswick, Rutgers University Press.

JoNEs, Charles A. (1972): "European bankers and Argentine, 1880-1890", Working Papers, núm. 3, Business Imperialism Series, Centre of Latin American Studies, University of Cambridge, $13 \mathrm{pp}$.

Josuin, David (1963): A Century of Banking in Latin America, Londres, Oxford University Press.

KORNER, K. W. (1956): "Apuntes para la historia del comercio argentino-alemán", Boletín de la Cámara de Comercio Argentino-Alemán, núms. 51-52.

LoRINI, Eteocle (1902-1910): La Repubblica Argentina $e$ i suoi migliori problemi di economia e di finanza, 3 vols., Roma.

Luxzmburgo, Rosa (1967): La acumulación del capital, México, Grijalbo.

Marichal, Carlos (1976): "Los ferrocarriles tranceses en la Argentina", Todo es Historia, núm. 105 , pp. 38-55.

MaURo, Frederic (1977): "Les investissements français en Amerique Latine, $\mathbf{x x}^{c}$ et $\mathrm{XX}^{c}$ siècles", en M. LEvy LzBoyER: La position internationale de la France: aspects économiques et financiers $\mathrm{XIX}^{*}$ et $\mathrm{XX} \cdot$ siècles, París, Ecole des Hautes, Etudes en Sciences Sociales, pp. 193 y ss.

Ministerio de Hacienda (República Argentina) (1870-1890): Memorias, Buenos Aires.

Money Market Review (1880-1890) (Periódico financiero inglés, anteriormente conocido como Investor's Journal and Money Market Review), Londres.

Mulhall, Michael (1885): Handbook of the River Plate, Buenos Aires y Londres.

NAYLOR, Tom (1975): The History of Canadian Business, 1867-1914, Toronto, J. Lo-

rimer.
Newron, Ronald C. (1977): German Buenos Aires, 1900-1933, Austin, University of Texas Press.

Pellegrini, Carlos (1941): Obras, precedido de un ensayo biográfico de A. R. Astengo, 5 vols., Buenos Aires.

Pex́, José B. (1907): Deuda argentina. Recopilación de leyes, decretos, resoluciones, notas y contratos sobre la Deuda pública nacional, 2 vols., Buenos Aires.

Peters, H. E. (1934): The Foreign Debt of the Argentine Republic, Baltimore, John Hopkins Press.

Pulado, Ricardo (1900): Anuario Pillado de la Deuda Priblica y Sociedades Anónimas, 2 vols., Buenos Aires.

Platt, D. C. M. (1980): "British Portfolio Investment Before 1870: Some Doubts", Economic History Review, dos series, vol. XXXIII, núm. 1, pp. 1-16.

- (1983): "Foreign Finance in Argentina for the first half century of independence", Journal of Latin American Studies, 15:1, pp. 23-47.

Sarato, Hilda (1983): "Wool trade and commercial networks in Buenos Aires, 1840's to 1880's", Journal of Latin American Studies, 15:1, pp. 49-81.

Saul, S. B. (1960): Studies in British Overseas Trade, 1870-1914, Liverpool, Liverpool University Press.

ScHIrT, Warren (1972): "The influence of the German armed forces and war industry on Argentina, 1880-1914", Hispanic American Historical Review, páginas 436-455.

ShEPHERD, Henry L. (1933): "Default and Adjustment of Argentine Foreign Debt", U. S. Department of Commerce, Trade Promotion Series, núm. 145, Washington, D. C., 65 pp. 
Smon, Mathew (1968): "The pattern of new British portfolio foreign investment, 1865-1914", en A. R. Hall (ed.): The Export of Capital from Britain, 1870-1914, Londres, Methuen, pp. 15-44.

Sommr, Luis (1948): La Revolución del 90, Buenos Aires.

South American Journal (1888-1890): Londres.

STERN, Fritz (1977): Gold and Iron: Bismark, Bleichroder and tre Building of the German Empire, Nueva York, A. Knopf.

Stone, Irving (1972): "British Investment in Argentina: A Note", Journal of Economic History, núm. de junio.

Trmant, Jules (1908): "Ernesto Tornquist et le commerce anversois, 1842-1908", Amberes, 58 pp.

ToRnquist Y Cí. (1924): Ernesto Tornquist y Cía., 1874-1924, Buenos Aires.

Whule, P. Barnett (1930): Joint Stock Banking in Germany. A Study of the German Credit Banks Before and After the War, Londres.

WIILAMs, John (1920): Argentine International Trade Under Inconvertible Paper Currency, 1880-1900, Cambridge, Harvard University Press.

ZaldUENDO, Eduardo (1975): Libras y rieles: las inversiones británicas para el desarrollo de los ferrocarriles en Argentina, Brasil, Canadá e India durante el siglo XIX, Buenos Aires, Ed. El Coloquio. 